\title{
Site localization of $\mathrm{Cd}$ impurities in sapphire
}

\author{
G. N. Darriba, ${ }^{1}$ M. Rentería, ${ }^{1}$ H. M. Petrilli, ${ }^{2}$ and L. V. C. Assali ${ }^{2}$ \\ ${ }^{1}$ Departamento de Física e Instituto de Física La Plata (IFLP, CONICET La Plata), Facultad de Ciencias Exactas, \\ Universidad Nacional de La Plata, Casilla de Correo 67, 1900 La Plata, Argentina \\ ${ }^{2}$ Universidade de São Paulo, Instituto de Física, DFMT, Caixa Postal 66318, CEP05315-970, São Paulo, SP, Brazil
}

(Received 13 July 2011; revised manuscript received 6 July 2012; published 9 August 2012)

\begin{abstract}
By combining first-principles electronic structure calculations and existing time-differential $\gamma-\gamma$ perturbedangular-correlation experiments we studied the site localization, the local environment, and the electronic structure of $\mathrm{Cd}$ impurities in sapphire $\left(\alpha-\mathrm{Al}_{2} \mathrm{O}_{3}\right)$ single crystals in different charged states. The ab initio calculations were performed with the full-potential augmented plane wave plus local orbitals method and the projector augmented wave method. Comparing the calculated electric-field-gradient tensor at the $\mathrm{Cd}$ nuclei in the $\alpha-\mathrm{Al}_{2} \mathrm{O}_{3}$ host lattice and the corresponding available experimental values, we have seen that it is equally possible for Cd to replace an $\mathrm{Al}$ atom (in a negative charge state) or to be placed in an interstitial site (in a neutral charge state). To finally address the issue of the $\mathrm{Cd}$ impurity localization, we performed formation energy calculations. These results have shown that $\mathrm{Cd}$ placed in the substitutional $\mathrm{Al}$ site, in the negatively charged state, is the most probable configuration.
\end{abstract}

DOI: 10.1103/PhysRevB.86.075203

PACS number(s): 61.72.U-, 61.72.jj, 71.15.Mb, 71.15.Nc

\section{INTRODUCTION}

Sapphire, the aluminum sesquioxide in the corundum phase $\left(\alpha-\mathrm{Al}_{2} \mathrm{O}_{3}\right)$, has a variety of technological applications such as high-temperature structural ceramics, dielectric insulators, spintronics, optical devices, and thin-film technology. An important application of ultrathin $\alpha-\mathrm{Al}_{2} \mathrm{O}_{3}$ is protection against corrosion and oxidation of the $\mathrm{Ni}-\mathrm{Al}$ alloy, ${ }^{1,2}$ widely applied as a bond coat on gas turbine components. In spintronics ${ }^{3,4}$ and in organic semiconductor devices, ${ }^{5} \mathrm{Al}_{2} \mathrm{O}_{3}$ has been used as a thin tunnel barrier in $\mathrm{Al}_{2} \mathrm{O}_{3} / \mathrm{Co}$ contacts, and individual $\mathrm{Fe}$ and $\mathrm{Co}$ atoms as well as small $\mathrm{Fe}$ clusters adsorbed on two atomic layers of $\mathrm{Al}_{2} \mathrm{O}_{3}$ grown on $\mathrm{Ni}_{3} \mathrm{Al}$ (111) have been investigated, with the aim of using them in classical information storage and quantum information processing. ${ }^{6}$

Many interesting properties are closely related to point defects and impurities introduced in $\mathrm{Al}_{2} \mathrm{O}_{3} \cdot{ }^{7-11}$ Ion implantation in alumina has been used to improve its optical and mechanical properties with applications in optics, optoelectronic devices, photonics, and tooling and, more recently, ion beam modification of sapphire seems to be an open field of research in the gemology industry. ${ }^{9,10}$ For example, ${ }^{7} \mathrm{Al}_{2} \mathrm{O}_{3}$ is a potential candidate to be used in emissive optical devices, exploiting the electronic properties of isolated impurities. On the other hand, small amounts of single-transition metal impurities are the most common cause of color in gemstones. An interesting example is the optical behavior of sapphire since when doped with $\mathrm{Ti}$ it is colorless, and when doped with $\mathrm{Fe}$ it is yellow, but when codoped with a small amount of both $\mathrm{Fe}$ and $\mathrm{Ti}$ it becomes deep blue. For this kind of process, $\mathrm{Cd}$, in the presence of an adjacent Ti ion in alumina, could be a potential candidate. Another important application of doped $\alpha-\mathrm{Al}_{2} \mathrm{O}_{3}$ is as sensors for $\mathrm{x}, \gamma$, and uv rays, where the presence of acceptor $\left(\right.$ as $\left.\mathrm{Mg}^{2+}\right)$ and donor $\left(\right.$ as $\left.\mathrm{Ti}^{4+}\right)$ metal impurities is essential to tune the promotion of relevant thermo-stimulatedluminescence peaks for dosimetric purposes. ${ }^{12}$ In this sense, the different electronic character of Cd impurities in $\alpha-\mathrm{Al}_{2} \mathrm{O}_{3}$ when located at substitutional $\mathrm{Al}$ sites (acceptor character) or at interstitial sites (donor character) converts $\mathrm{Cd}$ in a good dopant to be investigated for this application. Hence, a complete knowledge of structural and electronic properties of Cd-doped $\mathrm{Al}_{2} \mathrm{O}_{3}$ appears to be relevant.

Despite the tremendous development of theoretical calculations seen in the last decades, which have led to the possibility of studying and determining, with confidence, not only defect localization in solids but also of shedding light onto the corresponding perturbed electronic structure of the host, to our knowledge, no ab initio study for $\mathrm{Cd}$ in $\mathrm{Al}_{2} \mathrm{O}_{3}$ has been performed.

Hyperfine techniques have been extensively employed to investigate structural, electronic, and magnetic properties at the atomic scale in condensed matter. ${ }^{13,14}$ In particular, the solid-state nuclear technique time-differential $\gamma-\gamma$ perturbedangular correlations (TDPAC) can be employed in order to elucidate the subnanoscopic environment of the impurities or native atoms in solids. ${ }^{15-21}$ In this technique it is necessary to introduce, create, or activate a suitable probe isotope (often an impurity in the system under study), and the local information is imbricated as a product of a nuclear and an extranuclear quantity. For electric quadrupole hyperfine interactions, the nuclear quadrupole moment $(Q)$, characteristic of a given nuclear state with spin $I$, interacts with the electric-field-gradient (EFG) tensor at the nuclear probe position. The EFG can provide very precise information about the local environment of the probe atom and the electronic structure of the doped system since it is very sensitive to the anisotropic charge distribution close to the probe nucleus. Very accurate EFG calculations can nowadays be performed ${ }^{16,18,19,22,23}$ through the use of all-electron (AE) ab initio electronic structure calculations in the framework of the density functional theory (DFT) ${ }^{24}$ In these calculations, the host charge density, selfconsistently perturbed by the presence of the impurity, is determined. Hence, by confronting the theoretical calculations with the EFG inferred from measurements at a given site, we can investigate local characteristics as impurity energy levels, localization of impurities and defects, structural distortions, charge state of defect centers, etc. ${ }^{17-19,22,25-29}$ 
The $\mathrm{Cd}$ impurity site in $\mathrm{Cd}$-doped $\alpha-\mathrm{Al}_{2} \mathrm{O}_{3}$ has extensively been studied experimentally by TDPAC using single crystals implanted with radioactive tracers. Habenicht et al. ${ }^{30}$ performed TDPAC experiments using the ${ }^{111} \mathrm{In} \rightarrow{ }^{111} \mathrm{Cd}$ and the ${ }^{111 m} \mathrm{Cd} \rightarrow{ }^{111} \mathrm{Cd}$ decays, and Penner et al. ${ }^{31}$ used ${ }^{111} \mathrm{In} \rightarrow{ }^{111} \mathrm{Cd}$. In both experiments, the observed EFG was axially symmetric and, due to the excellent quality of the experimental spectra and to the presence of a very well-defined quadrupole interaction with a very small EFG distribution, the authors assigned the hyperfine interaction as generated by ${ }^{111} \mathrm{Cd}$ probes located at the substitutional Al site. We notice, however, that a single well-defined hyperfine interaction only proves that all ${ }^{111} \mathrm{Cd}$ occupy the same crystalline site, either substitutional or interstitial. On the other hand, in 1990 Farlow et al., ${ }^{32}$ using Rutherford backscattering/channeling spectroscopy (RBS/C), suggested that In impurities implanted in $\alpha-\mathrm{Al}_{2} \mathrm{O}_{3}$ occupy interstitial sites. These experiments were carried out for $\alpha-\mathrm{Al}_{2} \mathrm{O}_{3}$ single crystals implanted with a dose $10^{3}$ times larger than that used in the TDPAC experiments, ${ }^{30,31}$ giving the sample an amorphous character with Al-rich and Inrich zones where small $\mathrm{In}_{2} \mathrm{O}_{3}$ clusters were formed. Although the authors of TDPAC experiments assigned the hyperfine interactions to ${ }^{111} \mathrm{Cd}$ probes located at substitutional $\mathrm{Al}$ sites in $\alpha-\mathrm{Al}_{2} \mathrm{O}_{3}$, Marquez et al., ${ }^{33}$ based on the RBS/C measurements of Farlow et $a .^{32}$ and on semiempirical point charge model predictions, ${ }^{34,35}$ suggested that the ${ }^{111} \mathrm{Cd}$ probes could not be located at the substitutional Al sites. It should be noted that, as it is well known presently, the point charge model, and the use of the Sternheimer antishielding factor, ${ }^{36}$ which only depends on the given probe atom, are not adequate to reproduce the EFG at impurity sites in semiconductor oxides. ${ }^{17,18,23}$ On the other hand, it is worth noting that the RBS/C experiments ${ }^{32}$ were not performed in a system completely similar to those used in the TDPAC experiments.

Motivated to elucidate this controversy, here we perform a study of Cd-doped $\alpha-\mathrm{Al}_{2} \mathrm{O}_{3}$ using two state-of-the-art ab initio AE methods: the full-potential augmented plane wave plus local orbitals $(\mathrm{FP}-\mathrm{APW}+1 \mathrm{o})^{37}$ and the projector augmented wave (PAW). ${ }^{38}$ We consider different impurity sites (interstitial and substitutional) and charge states, since it is known that the presence of intrinsic defects and doping can modify the impurity charge state. In turn, the impurity charge state modifies the electronic and structural properties around the impurity, ${ }^{17,18,39}$ and both effects can strongly affect the resulting EFG. These theoretical EFG tensors are then compared to available experimental TDPAC results. ${ }^{30,31}$ Although the EFG has already been proved to be a powerful tool to identify impurity sites in metal oxides, ${ }^{17,19,25,27,28}$ to our knowledge, a deep study of the $\mathrm{Cd}$ localization in $\mathrm{Al}_{2} \mathrm{O}_{3}$ through a direct confrontation between measurements and reliable ab initio predictions has not been reported yet. Nevertheless, the situation faced in the present study is complicated by the fact that, in confronting experiments and ab initio EFG results, two possibly equivalent scenarios are found, and to further unravel this issue, we performed energetic studies.

This paper is organized as follows. In Sec. II we describe the theoretical approach used. In Sec. III B we present and discuss the theoretical results for electronic structure, structural relaxations, and EFGs for different charge states of substitutional and interstitial $\mathrm{Cd}$ impurities in $\alpha$ -
$\mathrm{Al}_{2} \mathrm{O}_{3}$; for comparison, we also revisit the undoped system (Section III A). In Sec. III C the impurity localization is discussed in the light of formation energy calculations considering different charge states and impurity localizations and, in Sec. IV, we present our conclusions. Finally, in the Appendix we show how the impurity formation energies are calculated.

\section{THEORETICAL APPROACH}

The EFG tensor components, at a nuclear position (taken as the origin of coordinates), are

$$
V_{i j}(\vec{r}=0)=\left.\frac{\partial^{2} V(\vec{r})}{\partial x_{i} \partial x_{j}}\right|_{\vec{r}=0},
$$

where $V(\vec{r})$ is the Coulomb potential created by the charge density surrounding the nucleus and $x_{i}$ are Cartesian coordinates. The $3 \times 3$ EFG tensor is traceless, symmetric, and diagonal (in the principal axes system). Therefore, with the usual convention $\left|V_{11}\right| \leqslant\left|V_{22}\right| \leqslant\left|V_{33}\right|$, it can be completely defined by only two quantities which are the largest component $V_{33}$ (referred as the EFG) and the asymmetry parameter

$$
\eta=\frac{V_{11}-V_{22}}{V_{33}} \text {. }
$$

The quantity obtained in a TDPAC experiment is the nuclear quadrupole frequency $\omega_{Q}$, which is related to $V_{33}$ through

$$
\omega_{Q}=\frac{e Q}{4 I(2 I-1) \hbar} V_{33} .
$$

Here $e$ is the proton's charge and $Q$ is the nuclear quadrupole moment of the sensitive nuclear level with spin $I$, of a TDPAC probe.

The dominant valence contributions to the EFG (Refs. 40 43) can usually be split into a $p-p\left(V_{33}^{p}\right)$ and a $d-d\left(V_{33}^{d}\right)$ part. These contributions are proportional to the $p$ and $d$ asymmetry counts $\Delta n_{p}$ and $\Delta n_{d}$, which are given in terms of the partial charges (occupation numbers) $n_{p_{i}}$ and $n_{d_{i}}$ of the corresponding $l_{i}$ orbital by

$$
\Delta n_{p}=\frac{1}{2}\left(n_{p_{x}}+n_{p_{y}}\right)-n_{p_{z}}
$$

and

$$
\Delta n_{d}=\left[\left(n_{d_{x^{2}-y^{2}}}+n_{d_{x y}}\right)\right]-\left[\frac{1}{2}\left(n_{d_{x z}}+n_{d_{y z}}\right)+n_{d_{z^{2}}}\right] .
$$

The $\alpha-\mathrm{Al}_{2} \mathrm{O}_{3}$ primitive unit cell is rhombohedral (space group $R \overline{3} c$ ) and contains two formula units. However, it is usually referred in a hexagonal structure which contains three primitive cells (12 $\mathrm{Al}$ and $18 \mathrm{O}$ atoms) with $a=b=$ 4.75999(3) $\AA$ and $c=12.99481$ (7) $\AA$ (Ref. 44), where the 12 Al occupy positions $\pm(0,0, u) ; \pm(0,0, u+1 / 2) ; r h$, and the $18 \mathrm{O}$ occupy the positions $\pm(v, 0,1 / 4) ; \pm(0, v, 1 / 4)$; $\pm(-v,-v, 1 / 4) ; r h ; r h$ implies adding $(1 / 3,2 / 3,2 / 3)$ and $(2 / 3,1 / 3,1 / 3)$ to the precedent coordinates, $u=0.35219(1)$ and $v=0.30633(5) .{ }^{44}$ Each $\mathrm{Al}$ atom has six oxygen nearest neighbors (ONN): three $(\mathrm{O} 1)$ at $1.854 \AA$ and three $(\mathrm{O} 2)$ at $1.972 \AA$.

We performed $a b$ initio electronic structure calculations for pure and Cd-doped systems using different cells: the primitive [Fig. 1(a)], the hexagonal [Fig. 1(b)], and a supercell 
(a)

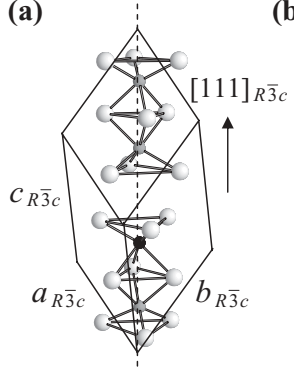

(b)

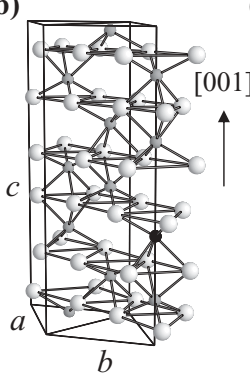

(c)

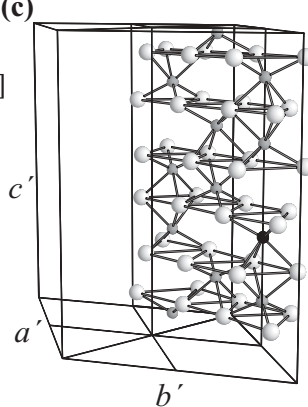

FIG. 1. Corundum $\alpha-\mathrm{Al}_{2} \mathrm{O}_{3}$ unit cell in (a) rhombohedral representation $(R \overline{3} c$ space group), (b) hexagonal representation, and (c) supercell with $a^{\prime}=2 a, b^{\prime}=2 b$, and $c^{\prime}=c$, used to simulate the 1:4 (a), 1:12 (b), and 1:48 (c) cation dilution of the impurity. The gray, white, and black spheres correspond to $\mathrm{Al}, \mathrm{O}$, and $\mathrm{Cd}$ atoms, respectively.

containing four hexagonal unit cells [Fig. 1(c)]. We used two different $a b$ initio AE methods to solve the KohnSham equations in the framework of the DFT: the FP$\mathrm{APW}+1 \mathrm{lo},{ }^{37}$ implemented in the WIEN2k code, ${ }^{45}$ and the PAW, ${ }^{38}$ implemented in the CP-PAW package, in combination with the Car-Parrinello ${ }^{46}$ ab initio molecular-dynamics approach. Exchange and correlation effects were treated using the Perdew, Burke, and Ernzerhof (PBE) ${ }^{47}$ functional. The charges were compensated by the addition of a homogeneous background ${ }^{48}$ in the electronic structure calculations of the charged systems. The self-consistent calculations included the total charge density and the EFG tensor was obtained directly from the second derivative of the full potential. ${ }^{41,49}$ The CP-PAW code uses a dampened motion to simultaneously determine the atomic positions and the electronic structure. In the WIEN $2 \mathrm{k}$ code, geometry optimizations are performed after the self-consistent electronic structure is achieved: Quantum mechanically derived forces are obtained and the ions are displaced, according to a Newton damped scheme ${ }^{50}$ in order to obtain the new positions. The procedure is repeated until the forces on the ions are below a tolerance value, here taken as $0.01 \mathrm{eV} / \AA$. The PAW basis $\operatorname{set}^{38}$ is constructed using plane waves and localized functions, which preserve the characteristic nodal structure close to the nuclei, with the "augmentation" concept specified by the so-called "projector functions." In the FP-APW + lo method ${ }^{37}$ the wave functions are expanded into spherical harmonics inside nonoverlapping spheres with radii $R_{M T}$, and in plane waves in the interstitial region. Since the EFG is extremely sensitive to small changes in the charge density around a given site, convergence was tested using the EFG values, instead of the total energy criteria. The PAW calculations were performed using $2 s, 2 p$, and $1 d$ projector functions for $\mathrm{Al}$ and $\mathrm{O}$, and $3 s, 3 p$, and $3 d$ for $\mathrm{Cd}$. We found in this case that a plane-wave cutoff of 70 Ry for the wave functions (and four times this value for the density), and eight (undoped) and 27 (doped) $k$ points sampling in the irreducible wedge of the Brillouin zone (IWBZ) provided EFGs that converged in less than $1 \%$ and Cd-ONN distances in less than $5 \times 10^{-3} \AA$. The same convergence was reached in the FP-APW + lo calculations, using $R_{M T}(\mathrm{Cd})=1.10 \AA$, $R_{M T}(\mathrm{Al})=0.87 \AA, R_{M T}(\mathrm{O})=0.85 \AA$ with five (undoped)

and 36 (doped) $k$ points to sample the IWBZ and $R K_{\max }=$ 7.0; this last parameter controls the size of the basis set in the interstitial region.

\section{RESULTS AND DISCUSSION}

\section{A. Undoped $\alpha-\mathrm{Al}_{2} \mathrm{O}_{3}$}

Before discussing the doped systems, it is worth reviewing the main results for the pure system. The optimized $u$ and $v$ $\alpha-\mathrm{Al}_{2} \mathrm{O}_{3}$ internal parameters obtained using the FP-APW + lo and PAW methods differ from the experimental literature values by less than $1 \times 10^{-3}$. Adopting the experimental structure, both theoretical approaches provide $+0.62 \times 10^{21} \mathrm{~V} / \mathrm{m}^{2}$ as the EFG value at the $\mathrm{Al}$ site, oriented along the [001] crystalline axis in the hexagonal cell [i.e., the $c$ axis, see Fig. 1(b)], and $\eta=$ 0.00 , in agreement with the symmetry of the cation site in the lattice. These results are in excellent agreement with nuclear magnetic resonance (NMR) results at ${ }^{27} \mathrm{Al}$ in $\alpha-\mathrm{Al}_{2} \mathrm{O}_{3},{ }^{51}$ where $V_{33}=+0.67(2) \times 10^{21} \mathrm{~V} / \mathrm{m}^{2}$ and $\eta=0.08(3)$. Since this experiment was carried out on a polycrystalline sample, the $V_{33}$ direction could not be determined. Using the theoretically optimized structural parameters, the $V_{33}$ values are $+0.59 \times 10^{21} \mathrm{~V} / \mathrm{m}^{2}\left(\right.$ FP-APW + lo) and $+0.60 \times 10^{21} \mathrm{~V} / \mathrm{m}^{2}$ (PAW). All these results are very similar (the EFG value is indeed small) and reproduce what some of us, using the Full-Potential Linearized Augmented Plane Wave (FP-LAPW) method, previously obtained. ${ }^{28}$

The total density of states (DOS), obtained using the FP-APW + lo method, is shown in Fig. 2(a). The valence band has mainly O-2 $p$ character, whereas the conduction band is predominantly described by $\mathrm{Al}-3 s$ and $3 p$ orbitals, in agreement with previous theoretical results. ${ }^{52-55}$ Our theoretical band gap is $6.2 \mathrm{eV}(\mathrm{FP}-\mathrm{APW}+\mathrm{lo})$ and $5.8 \mathrm{eV}$ (PAW),
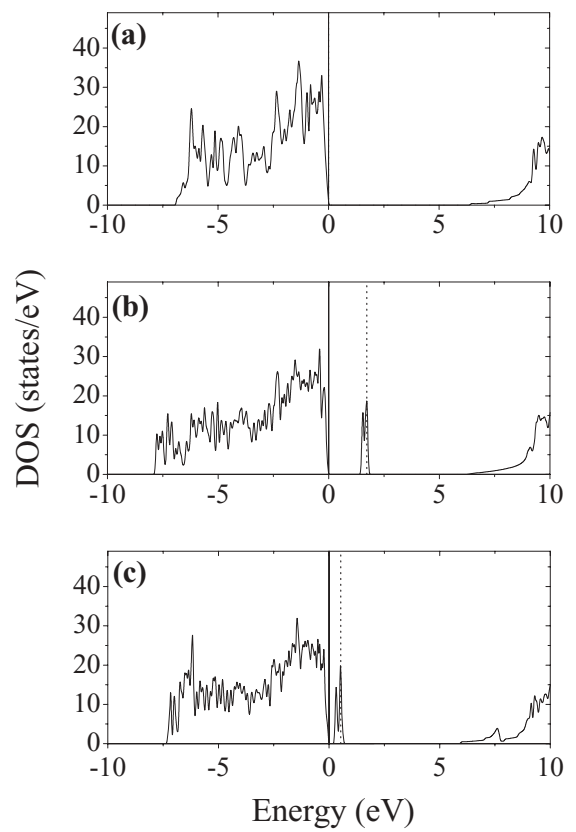

FIG. 2. Total density of states (DOS) of (a) pure $\alpha-\mathrm{Al}_{2} \mathrm{O}_{3}$, (b) $\left(\mathrm{Al}_{2} \mathrm{O}_{3}: \mathrm{Cd}_{\mathrm{s}}\right)^{0}$, and (c) relaxed $\left(\mathrm{Al}_{2} \mathrm{O}_{3}: \mathrm{Cd}_{\mathrm{s}}\right)^{0}$. The vertical lines are at the top of the valence band (solid) and at the highest occupied state (dotted). In (a) both lines are coincident. 
whereas an optical gap of $8.8 \mathrm{eV}$ has been measured. ${ }^{56}$ The underestimation of the band gap, especially in metal oxides, is a well-known DFT deficiency, but it has been shown ${ }^{39}$ that this does not interfere with the calculations of observables which depend only on the ground state, such as the EFG.

\section{B. Cd-doped $\alpha-\mathrm{Al}_{2} \mathrm{O}_{3}$}

From here on we establish the following notation for the Cd-doped $\alpha-\mathrm{Al}_{2} \mathrm{O}_{3}$ systems: $\mathrm{Al}_{2} \mathrm{O}_{3}: \mathrm{Cd}_{\mathrm{s}}$, when the $\mathrm{Cd}$ impurity substitutes an $\mathrm{Al}$ atom and $\mathrm{Al}_{2} \mathrm{O}_{3}: \mathrm{Cd}_{\mathrm{i}}$, when the $\mathrm{Cd}$ impurity is located in an interstitial site.

To simulate the $\mathrm{Cd}$ impurity dilution in $\mathrm{Al}_{2} \mathrm{O}_{3}: \mathrm{Cd}_{\mathrm{s}}$ we replaced an $\mathrm{Al}$ by a $\mathrm{Cd}$ in the unit cell of Fig. 1(b), obtaining a 1:12 impurity cation dilution, which is three times larger than that obtained using the rhombohedral representation [Fig. 1(a)]. To check if the 1:12 dilution is sufficient to simulate the parts per million impurity dilution used in the ${ }^{111} \mathrm{Cd}$-doped $\alpha-\mathrm{Al}_{2} \mathrm{O}_{3}$ PAC experiments, we performed ab initio EFG calculations using a supercell containing four hexagonal unit cells $(2 \times 2 \times 1)$ with dimensions $a^{\prime}=2 a, b^{\prime}=2 b$, and $c^{\prime}=$ $c\left(a^{\prime} / c^{\prime}=0.73\right)$, obtaining a 1:48 impurity cation dilution, as shown in Fig. 1(c). The $V_{33}$ results, obtained using these three unit cells, are shown in Fig. 3, as a function of the number of steps in the atomic relaxation process in the FP-APW + lo calculation. Since when using the initial (unrelaxed) atomic positions, the EFGs are basically the same in the three cases, we see that the periodic images of the impurities do not interact, even in the 1:4 dilution. Nevertheless, although the $\mathrm{Cd}-\mathrm{Cd}$ nearest neighbors distances are almost equal in the 1:4 and 1:12 dilutions, the ONNs are able to freely relax only in the $1: 12$ case [Fig. 1(b)] since, contrary to what happens in the 1:4 [Fig. 1(a)], the ONNs of both Cd impurities are not adjacent. This leads to the general superposition of the EFG values, as shown in Fig. 3, for the 1:12 and 1:48 dilutions, and deviation of the 1:4 EFG curve as the relaxation processes take place. Due to this fact, we have used the 1:12 hexagonal cell [Fig. 1(b)] in the following analysis.

We also used the hexagonal representation of the unit cell (with $12 \mathrm{Al}$ and $18 \mathrm{O}$ atoms) to construct the $\mathrm{Al}_{2} \mathrm{O}_{3}: \mathrm{Cd}_{\mathrm{i}}$ system, and added a $\mathrm{Cd}$ atom in the $(0,0,1 / 2)$ position. The Cd impurity neighborhood is made by six ONNs at

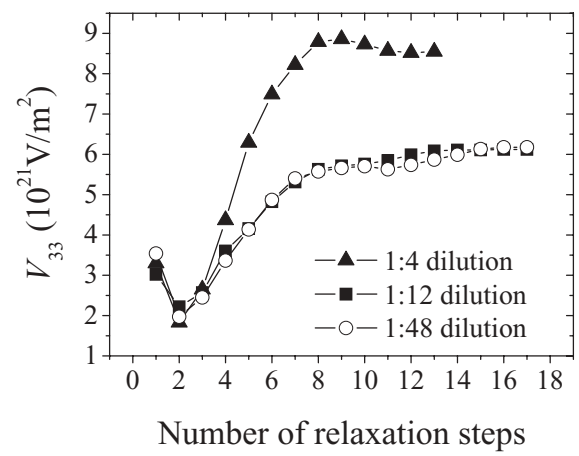

FIG. 3. $V_{33}$ as a function of the number of steps in the atomic relaxation process, starting from the ideal experimental positions (left side) towards the final equilibrium positions, for the three $\left(\mathrm{Al}_{2} \mathrm{O}_{3}: \mathrm{Cd}_{\mathrm{s}}\right)^{0}$ cells shown in Fig. 1 . the same $1.977 \AA \mathrm{Cd}-\mathrm{ONN}$ distance (a value similar to the substitutional case). We have chosen this interstitial site since it is axially symmetric, as required by the $\eta_{\text {expt }}=0$ experimental results.

\section{Substitutional Cd}

The total DOS for the neutral charge state unit cell, $\left(\mathrm{Al}_{2} \mathrm{O}_{3}: \mathrm{Cd}_{\mathrm{s}}\right)^{0}$, with all atoms in their initial unrelaxed positions, is shown in Fig. 2(b). Comparing with Fig. 2(a) we see that the presence of the $\mathrm{Cd}$ impurity induces the appearance of Cd-4d levels as partially filled impurity states into the band gap. The total DOS obtained after structural relaxations is shown in Fig. 2(c), where we see that the impurity energy levels move towards the top of the valence band. Integration of the DOS in the unfilled energy region of this peak gives a value of 1.1 electrons, which agrees with the nominal single-acceptor character of substitutional $\mathrm{Cd}$ in $\mathrm{Al}_{2} \mathrm{O}_{3}$. Therefore, we have considered a charged system, from here on denoted by $\left(\mathrm{Al}_{2} \mathrm{O}_{3}: \mathrm{Cd}_{\mathrm{s}}\right)^{1-}$, by adding one electron to the unit cell.

Although the experimental TDPAC results ${ }^{30,31}$ do not suggest any magnetism present in $\alpha-\mathrm{Al}_{2} \mathrm{O}_{3}:{ }^{111} \mathrm{Cd}$, we have also performed spin-polarized calculations and obtained a very small $\left(0.12 \mu_{\mathrm{B}}\right)$ local magnetic moment at the $\mathrm{Cd}$ site in the case of the neutral charge state. In both spin-polarized and non-spin-polarized calculations, the EFG results and total energies are the same.

The structural and EFG results are shown in Table I and, in all cases (including the experimental), [001] is the $V_{33}$ direction. The substitution of an $\mathrm{Al}$ by a $\mathrm{Cd}$ impurity (with unrelaxed positions), produces significant changes in the EFG tensor $\left(V_{33}\right.$ varies from $+0.62 \times 10^{21} \mathrm{~V} / \mathrm{m}^{2}$ at the Al site to $+3.08 \times 10^{21} \mathrm{~V} / \mathrm{m}^{2}$ at the $\mathrm{Cd}$ site), whereas the symmetry and orientations are not changed. These differences in the EFG magnitude just illustrate the large electronic contribution of the Cd impurity to the EFG. Both FP-APW + lo and PAW calculations lead to the same EFG value and, therefore, since the EFG is highly sensitive to very small changes in the charge density, to the same electronic structure. The substitution of an $\mathrm{Al}$ atom by a $\mathrm{Cd}$ impurity produces non-negligible forces on its nearest neighbors and displacements of all atoms in the unit cell were allowed. The equilibrium distances, $d_{\mathrm{Cd}-\mathrm{O} 1}$ and $d_{\mathrm{Cd}-\mathrm{O} 2}$, from $\mathrm{Cd}$ to its $\mathrm{ONN}$ in $\left(\mathrm{Al}_{2} \mathrm{O}_{3}: \mathrm{Cd}_{\mathrm{s}}\right)^{0}$ and $\left(\mathrm{Al}_{2} \mathrm{O}_{3}: \mathrm{Cd}_{\mathrm{s}}\right)^{1-}$ are presented in Table I. The Cd-ONN distances are enlarged upon structural relaxations and almost exactly the same final distances are predicted using the two theoretical approaches. It is interesting to notice that the $\mathrm{Cd}-\mathrm{O} 1$ distance is almost the same in both charge states. In Fig. 4(a) we show the equilibrium positions for the $\left(\mathrm{Al}_{2} \mathrm{O}_{3}: \mathrm{Cd}_{\mathrm{s}}\right)^{1-}$. The $\mathrm{O} 1$ atoms relax outwards, enlarging the triangle formed by them in the $a-b$ plane, whereas the $\mathrm{O} 2$ also relax outwards but in the [001] direction. The final $\mathrm{Cd}-\mathrm{Al}$ distance is enlarged by $7 \%$, for both impurity charge states, moving along the $c$ axis. These structural distortions could be expected from a simple ionic radii size effect analysis, since the ionic radius for sixfold coordinated $\mathrm{Al}^{+3}$ is $0.55 \AA$, which is smaller than the $0.95 \AA$ value for $\mathrm{Cd}^{+2} .{ }^{57}$ As it has been observed previously in $\mathrm{Cd}$-doped $\mathrm{In}_{2} \mathrm{O}_{3},{ }^{26} \mathrm{Lu}_{2} \mathrm{O}_{3},{ }^{27} \mathrm{SnO}_{2},{ }^{25}$ and $\mathrm{TiO}_{2},{ }^{17,18}$ the presence of the $\mathrm{Cd}$ impurity favors the reconstruction of the 
TABLE I. Largest component $V_{33}$ of the EFG tensor and asymmetry parameter $\eta$ at $\mathrm{Cd}$ substitutionally localized at the $\mathrm{Al}$ site in $\alpha$ - $\mathrm{Al}_{2} \mathrm{O}_{3}$ obtained using the FP-APW + lo and PAW methods. Also shown are the experimental TDPAC results. Distances $\mathrm{Cd}-\mathrm{ONN}, d_{\mathrm{Cd}-\mathrm{O} 1}$, and $d_{\mathrm{Cd}-\mathrm{O} 2}$ [according to Fig. 4(a)].

\begin{tabular}{|c|c|c|c|c|c|}
\hline & & $d_{\mathrm{Cd}-\mathrm{O} 1}(\AA)$ & $d_{\mathrm{Cd}-\mathrm{O} 2}(\AA)$ & $V_{33}\left(10^{21} \mathrm{~V} / \mathrm{m}^{2}\right)$ & $\eta$ \\
\hline \multirow{2}{*}{$\left(\mathrm{Al}_{2} \mathrm{O}_{3}: \mathrm{Cd}_{\mathrm{s}}\right)^{0}$ (unrelaxed structure) } & FP-APW + lo & 1.854 & 1.972 & +3.00 & 0.00 \\
\hline & PAW & 1.854 & 1.972 & +3.08 & 0.00 \\
\hline \multirow[t]{2}{*}{$\left(\mathrm{Al}_{2} \mathrm{O}_{3}: \mathrm{Cd}_{\mathrm{s}}\right)^{0}($ relaxed structure $)$} & FP-APW + lo & 2.070 & 2.257 & +6.12 & 0.00 \\
\hline & PAW & 2.075 & 2.260 & +6.31 & 0.00 \\
\hline \multirow{2}{*}{$\left(\mathrm{Al}_{2} \mathrm{O}_{3}: \mathrm{Cd}_{\mathrm{s}}\right)^{1-}$ (unrelaxed structure) } & FP-APW + lo & 1.854 & 1.972 & +4.78 & 0.00 \\
\hline & PAW & 1.854 & 1.972 & +4.43 & 0.00 \\
\hline \multirow[t]{2}{*}{$\left(\mathrm{Al}_{2} \mathrm{O}_{3}: \mathrm{Cd}_{\mathrm{s}}\right)^{1-}($ relaxed structure $)$} & FP-APW + lo & 2.066 & 2.323 & +10.73 & 0.00 \\
\hline & PAW & 2.070 & 2.323 & +10.34 & 0.00 \\
\hline Experimental $^{\mathrm{a}}$ & ${ }^{111} \mathrm{In} \rightarrow{ }^{111} \mathrm{Cd}$ & - & - & $10.8(2)$ & 0.00 \\
\hline Experimental $^{\mathrm{b}}$ & ${ }^{111} \mathrm{In} \rightarrow{ }^{111} \mathrm{Cd}$ & - & - & $10.9(1)$ & 0.00 \\
\hline Experimental $^{\mathrm{a}}$ & ${ }^{111 m} \mathrm{Cd} \rightarrow{ }^{111} \mathrm{Cd}$ & - & - & $10.8(2)$ & 0.00 \\
\hline
\end{tabular}

${ }^{\mathrm{a}}$ Reference 30.

${ }^{\mathrm{b}}$ Reference 31 .

Cd-O bond length in its own oxide, $\mathrm{CdO}$, which is $2.35 \AA$. This value is almost reached for the $\mathrm{Cd}-\mathrm{O} 2$ bond length $(2.323 \AA)$ in the charged system. The EFG results presented in Table I are very much dependent on structural relaxations and impurity charge state, suggesting that the electron was mainly added at the $\mathrm{Cd}$ site. Moreover, for substitutional $\mathrm{Cd}$, the $\left(\mathrm{Al}_{2} \mathrm{O}_{3}: \mathrm{Cd}_{\mathrm{s}}\right)^{1-}$ system is the only one that reproduces the experimental results, showing that the deep acceptor level is ionized already at $4 \mathrm{~K}$ in this scenario. ${ }^{31}$ It is worth mentioning that the EFG sign was not measured in the TDPAC experiments of Refs. 30 and 31 .

In order to understand our EFG results, we show in Table II the $s, p$, and $s$ - $d$ valence contributions to the EFG at the Cd site in $\left(\mathrm{Al}_{2} \mathrm{O}_{3}: \mathrm{Cd}_{\mathrm{s}}\right)^{0}$ and $\left(\mathrm{Al}_{2} \mathrm{O}_{3}: \mathrm{Cd}_{\mathrm{s}}\right)^{1-}$. In agreement with previous studies in different metal-doped systems ${ }^{18,40}$ the Cd-5 $p$ contribution dominates over the $d$ contribution, which is due to the fact that the first node of the $5 p$ wave function is at a much shorter distance than the one of the $4 d$ wave function, 40 although the $d$ charge-density anisotropy $\Delta n_{d}$ is larger than $\Delta n_{p}$ (not shown here). The partial $p$ and $d$ density of states (PDOS) projected at the $\mathrm{Cd}$ sites are shown in Fig. 5(a) for $\left(\mathrm{Al}_{2} \mathrm{O}_{3}: \mathrm{Cd}_{\mathrm{s}}\right)^{0}$ (left) and $\left(\mathrm{Al}_{2} \mathrm{O}_{3}: \mathrm{Cd}_{\mathrm{s}}\right)^{1-}$ (right); the $p$ PDOS at the corresponding $\mathrm{O} 1$ and $\mathrm{O} 2$ sites are shown in Fig. 5(b). Only the energy region around the impurity gap state is shown. For the two charge states the $p_{z}$ contribution to the $p$ PDOS (a)

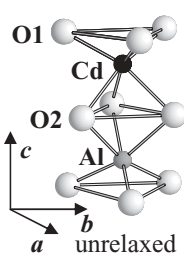

(b)

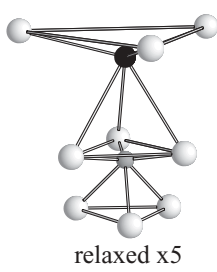

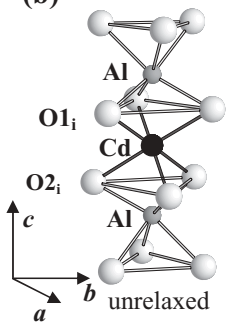

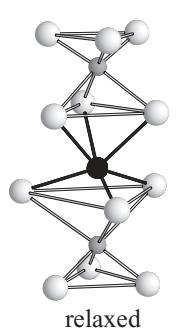

FIG. 4. Final equilibrium positions of the Cd impurity and its oxygen nearest neighbors for (a) substitutional $\mathrm{Cd}$ in the $\mathrm{Al}$ site in $\left(\mathrm{Al}_{2} \mathrm{O}_{3}: \mathrm{Cd}_{\mathrm{s}}\right)^{1-}$ (the relaxations are magnified five times) and (b) $\mathrm{Cd}$ located at the interstitial site in $\left(\mathrm{Al}_{2} \mathrm{O}_{3}: \mathrm{Cd}_{\mathrm{i}}\right)^{0}$. is important in the case of $\mathrm{O} 2$ while it is negligible in the case of $\mathrm{O} 1$ which is related to the fact that, after structural relaxation, the $\mathrm{Cd}-\mathrm{O} 1$ bonds are mostly in the $x$-y plane [ $a-b$ plane in Fig. 4(a)] and the $\mathrm{Cd}-\mathrm{O} 2$ bonds have a larger $z$ projection [along the $c$ axis in Fig. 4(a)]. It is interesting to notice that the difference among the EFG at the Cd site in the two charge states cannot be understood only by inspecting the energy region shown in Fig. 5(a). As we see, the $d_{z^{2}}$ and $p_{z}$ Cd PDOS almost vanish providing a negligible contribution to the EFG in the neutral state [Fig. 5(a), left]. When we add one electron to the system [Fig. 5(a), right], the gap impurity level becomes completely filled, without significant changes in the overall shape of the $d$ and $p$ PDOS. By comparing the left and right sides of Fig. 5(a), we could have concluded, for example, that the increase in $V_{33}^{p}$ is due to the fact that $n_{p_{x}}$ and $n_{p_{y}}$ are larger in the charged system and $n_{p_{z}}$ almost does not change [see Eq. (4)]. Nevertheless, the strongest change in the EFG is caused by small differences among the occupation of different orbitals [see Eqs. (4) and (5)], which results from the integration of the Cd- $p$ PDOS over the entire energy range and not only in the gap impurity level region. In Fig. 6 we show the $p$ and $d$ PDOS at the Cd site in $\left(\mathrm{Al}_{2} \mathrm{O}_{3}: \mathrm{Cd}_{\mathrm{s}}\right)^{0}$ and $\left(\mathrm{Al}_{2} \mathrm{O}_{3}: \mathrm{Cd}_{\mathrm{s}}\right)^{1-}$ for the whole valence band. We see that the $\mathrm{Cd}$ impurity introduces mainly $d$ states at the bottom of the valence band ( -7.4 to $-6.6 \mathrm{eV}$ region in Fig. 6 , to the left) and the $d_{z^{2}}$ and $p_{z}$ PDOSs are not vanishing anymore. Indeed, our results show that the $V_{33}^{p}$ increase (when we add one electron)

TABLE II. $p, d$, and $s$ - $d$ valence contributions to the EFG tensor principal components $V_{i i}$ (in units of $10^{21} \mathrm{~V} / \mathrm{m}^{2}$ ) at $\mathrm{Cd}$ in the Al site in $\alpha-\mathrm{Al}_{2} \mathrm{O}_{3}$, for neutral and negative charge states calculated with the FP-APW + lo method.

\begin{tabular}{lcccccccc}
\hline \hline & \multicolumn{3}{c}{$\left(\mathrm{Al}_{2} \mathrm{O}_{3}: \mathrm{Cd}_{\mathrm{s}}\right)^{0}$} & & \multicolumn{3}{c}{$\left(\mathrm{Al}_{2} \mathrm{O}_{3}: \mathrm{Cd}_{\mathrm{s}}\right)^{1-}$} \\
\cline { 2 - 4 } \cline { 6 - 8 } & $V_{11}$ & $V_{22}$ & $V_{33}$ & & $V_{11}$ & $V_{22}$ & $V_{33}$ \\
\hline$p$ & -3.11 & -3.11 & +6.23 & & -4.53 & -4.53 & +9.06 \\
$d$ & -0.01 & -0.01 & +0.02 & & -0.94 & -0.94 & +1.88 \\
$s-d$ & +0.07 & +0.07 & -0.15 & & +0.10 & +0.10 & -0.21 \\
\hline \hline
\end{tabular}



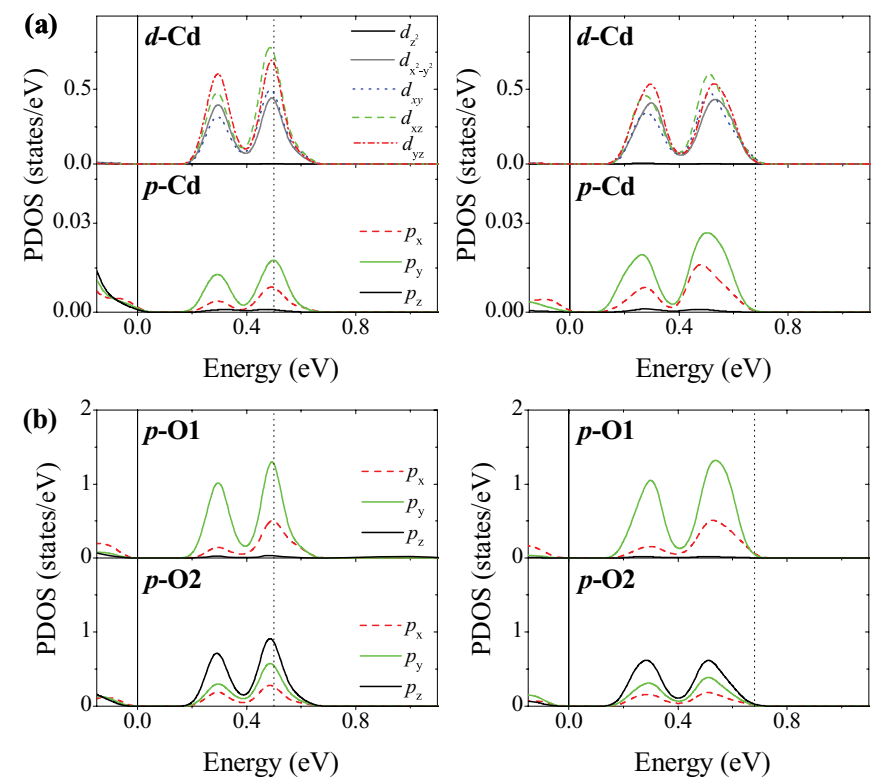

FIG. 5. (Color online) Partial density of states (PDOS) of (a) $d$ and $p$ contributions projected at the Cd site, (b) $p$ contribution projected at the $\mathrm{O} 1$ and $\mathrm{O} 2$ sites, for $\left(\mathrm{Al}_{2} \mathrm{O}_{3}: \mathrm{Cd}_{\mathrm{s}}\right)^{0}$ (on the left) and $\left(\mathrm{Al}_{2} \mathrm{O}_{3}: \mathrm{Cd}_{\mathrm{s}}\right)^{1-}$ (on the right). The vertical lines are at the top of the valence band (solid) and at the highest occupied state (dotted).

is due to a $n_{p_{z}}$ decrease, a variation which is one order of magnitude larger than the $n_{p_{x}}$ and $n_{p_{y}}$ increase. The weak increase of the $V_{33}^{d}$ contribution can be explained in a similar way.

\section{Interstitial Cd}

In the previous sections, we have shown that the results obtained with the PAW and FP-APW + lo methods are very similar. Therefore, we will proceed, in the case of $\mathrm{Cd}$ doping at the interstitial site by just reporting the results obtained with the PAW method.

Structural and EFG results obtained with the CP-PAW code for impurity charge states $\left(\mathrm{Al}_{2} \mathrm{O}_{3}: \mathrm{Cd}_{\mathrm{i}}\right)^{0}$ and $\left(\mathrm{Al}_{2} \mathrm{O}_{3}: \mathrm{Cd}_{\mathrm{i}}\right)^{2+}$ are shown in Table III. The $\left(\mathrm{Al}_{2} \mathrm{O}_{3}: \mathrm{Cd}_{\mathrm{i}}\right)^{0}$ structures, before and after structural relaxations, are shown in Fig. 4(b). Upon relaxations the triangle formed by the $\mathrm{O} 2$ i atoms in the $a-b$ plane is enlarged since the $\mathrm{O} 2{ }_{\mathrm{i}}$ atoms relax outwards, whereas
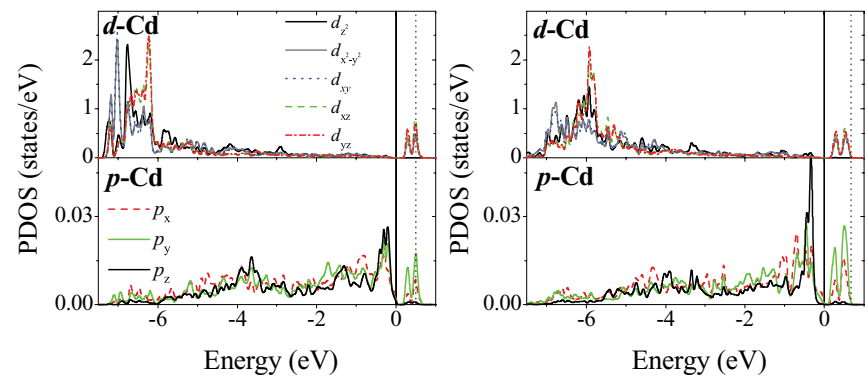

FIG. 6. (Color online) Partial $d$ and $p$ density of states (PDOS) projected at the $\mathrm{Cd}$ site for $\left(\mathrm{Al}_{2} \mathrm{O}_{3}: \mathrm{Cd}_{\mathrm{s}}\right)^{0}$ (left) and $\left(\mathrm{Al}_{2} \mathrm{O}_{3}: \mathrm{Cd}_{\mathrm{s}}\right)^{1-}$ (right). The vertical lines are at the top of the valence band (solid) and at the highest occupied state (dotted).

the $\mathrm{O}_{\mathrm{i}}$ atoms move mainly in the [001] direction. The $\mathrm{Cd}$ impurity and its two $\mathrm{Al}$ nearest neighbors move along the $c$ axis. The $d_{\mathrm{Cd}-\mathrm{O} 1_{\mathrm{i}}}$ and $d_{\mathrm{Cd}-\mathrm{O} 2_{\mathrm{i}}}$ (Table III) depend strongly on the charge state and are considerably larger in $\left(\mathrm{Al}_{2} \mathrm{O}_{3}: \mathrm{Cd}_{\mathrm{i}}\right)^{0}$ than in $\left(\mathrm{Al}_{2} \mathrm{O}_{3}: \mathrm{Cd}_{\mathrm{i}}\right)^{2+}$. As already observed in the substitutional case, the final $\mathrm{Cd}-\mathrm{ONN}$ equilibrium distances in $\left(\mathrm{Al}_{2} \mathrm{O}_{3}: \mathrm{Cd}_{\mathrm{i}}\right)^{0}$ go towards the reconstruction of the $\mathrm{Cd}-\mathrm{O}$ bond length $(2.35 \AA)$ in its own oxide $(\mathrm{CdO})$. We also note that structural relaxations are larger in $\left(\mathrm{Al}_{2} \mathrm{O}_{3}: \mathrm{Cd}_{\mathrm{i}}\right)^{0}$ than in $\left(\mathrm{Al}_{2} \mathrm{O}_{3}: \mathrm{Cd}_{\mathrm{s}}\right)^{0}$ since, due to the repulsion of the nearest neighbors $\mathrm{Al}$ which are above and below (along the $c$ direction) the $\mathrm{Cd}$ atom, more space is allowed for the $\mathrm{O} 1_{\mathrm{i}}$ and $\mathrm{O} 2_{\mathrm{i}}$ relaxations. In accordance with the lattice relaxations introduced by the interstitial $\mathrm{Cd}$ atoms, the electronic structure changes upon lattice relaxations are very large, as shown from the EFG results presented in Table III. These theoretical EFGs are also very sensitive to the charge state, a fingerprint of electron density modifications close to the interstitial impurity site produced by the removal of two electrons in the unit cell. In the doubly charged case, as could be expected for a completely closed $4 d^{10}$ shell situation, the $\mathrm{EFG}$ at the $\mathrm{Cd}$ site almost vanishes, a magnitude that is very far from the experimental results. Due to this fact, this interstitial doubly charged defect center can be ruled out. On the other hand, most important here is the fact that the predicted EFG at the interstitial Cd site in the $\left(\mathrm{Al}_{2} \mathrm{O}_{3}: \mathrm{Cd}_{\mathrm{i}}\right)^{0}$ neutral system is in excellent agreement with the absolute $\mathrm{EFG}$ value obtained in the TDPAC experiments. ${ }^{30,31}$ This theoretical scenario would imply that the observed interstitial defect center would not be ionized, at least, in the wide $4-973 \mathrm{~K}$ temperature range. ${ }^{31}$

TABLE III. Largest component $V_{33}$ of the EFG tensor and asymmetry parameter $\eta$ at $\mathrm{Cd}$ localized at the interstitial site $\left(\mathrm{Cd}_{\mathrm{i}}\right)$ obtained using the PAW method. Also shown are the experimental TDPAC results. Distances $\mathrm{Cd}_{\mathrm{i}}-\mathrm{ONN}, d_{\mathrm{Cd}-\mathrm{O} 1_{\mathrm{i}}}$ and $d_{\mathrm{Cd}-\mathrm{O} 2_{\mathrm{i}}}[$ according to Fig. 4(b)].

\begin{tabular}{lccrr}
\hline \hline & & $d_{\mathrm{Cd}-\mathrm{O} 1_{\mathrm{i}}}(\AA)$ & $d_{\mathrm{Cd}-\mathrm{O} 2_{\mathrm{i}}-}(\AA)$ & $V_{33}\left(10^{21} \mathrm{~V} / \mathrm{m}^{2}\right)$ \\
\hline$\left(\mathrm{Al}_{2} \mathrm{O}_{3}: \mathrm{Cd}_{\mathrm{i}}\right)^{0}$ & Unrelaxed structure & 1.977 & 1.977 & -3.15 \\
$\left(\mathrm{Al}_{2} \mathrm{O}_{3}: \mathrm{Cd}_{\mathrm{i}}\right)^{0}$ & Relaxed structure & 2.31 & 2.37 & -10.25 \\
$\left(\mathrm{Al}_{2} \mathrm{O}_{3}: \mathrm{Cd}_{\mathrm{i}}\right)^{2+}$ & Unrelaxed structure & 1.977 & 1.977 & 0.00 \\
$\left(\mathrm{Al}_{2} \mathrm{O}_{3}: \mathrm{Cd}_{\mathrm{i}}\right)^{2+}$ & Relaxed structure & 2.125 & 2.125 & 0.01 \\
Experimental $^{\mathrm{a}}$ & ${ }^{111} \mathrm{In} \rightarrow{ }^{111} \mathrm{Cd}$ & - & - & 0.00 \\
Experimental $^{\mathrm{b}}$ & ${ }^{111} \mathrm{In} \rightarrow{ }^{111} \mathrm{Cd}$ & - & - & 0.62 \\
Experimental $^{\mathrm{a}}$ & ${ }^{111 m} \mathrm{Cd} \rightarrow{ }^{111} \mathrm{Cd}$ & - & - & 0.00 \\
\hline \hline
\end{tabular}

${ }^{\mathrm{a}}$ Reference 30.

${ }^{\mathrm{b}}$ Reference 31 . 

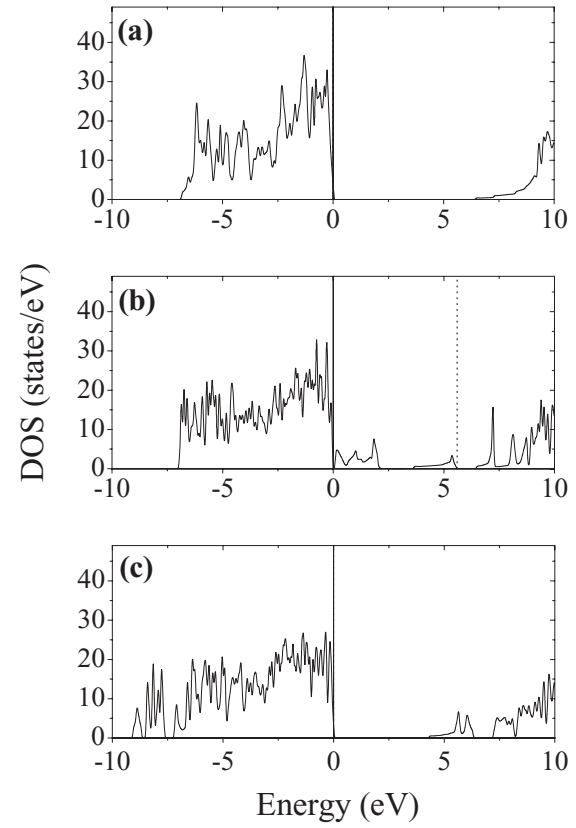

FIG. 7. Total density of states (DOS) of (a) pure $\alpha-\mathrm{Al}_{2} \mathrm{O}_{3}$, (b) $\left(\mathrm{Al}_{2} \mathrm{O}_{3}: \mathrm{Cd}_{\mathrm{i}}\right)^{0}$, and (c) $\left(\mathrm{Al}_{2} \mathrm{O}_{3}: \mathrm{Cd}_{\mathrm{i}}\right)^{2+}$. The vertical lines are at the top of the valence band (solid) and at the highest occupied state (dotted). In (a) and (c) both lines are coincident.

Nevertheless, we have shown in Sec. III B 1 that the EFG value at the substitutional $\mathrm{Cd}$ site in $\left(\mathrm{Al}_{2} \mathrm{O}_{3}: \mathrm{Cd}_{\mathrm{s}}\right)^{1-}$ also matches the observed TDPAC result.

In Fig. 7 we show the total DOS for $\alpha-\mathrm{Al}_{2} \mathrm{O}_{3}$ [Fig. 7(a)], $\left(\mathrm{Al}_{2} \mathrm{O}_{3}: \mathrm{Cd}_{\mathrm{i}}\right)^{0}$ [Fig. 7(b)], and $\left(\mathrm{Al}_{2} \mathrm{O}_{3}: \mathrm{Cd}_{\mathrm{i}}\right)^{2+}$ [Fig. 7(c)]. Comparing Figs. 7(a) and 7(b) we see the appearance of a broad occupied band in the band gap and unoccupied localized impurity states near the bottom of the conduction band. In Fig. 8 (left) we show the $d$ and $p$ PDOS projected at the Cd site and in Fig. 9 (left) the $p$ PDOS at the $\mathrm{O}_{1}$ and $\mathrm{O} 2_{\mathrm{i}}$ $(\mathrm{Cd}$ nearest neighbors $)$ in the $\left(\mathrm{Al}_{2} \mathrm{O}_{3}: \mathrm{Cd}_{\mathrm{i}}\right)^{0}$ system. We see that the deeper impurity levels appearing in the gap region (from 0.1 to $2.2 \mathrm{eV}$ ) have basically $\mathrm{O} 2 \mathrm{i}_{\mathrm{i}}-2 p$ and a small Cd-5p contribution. The highest impurity states in the band gap (from 3.6 to $5.6 \mathrm{eV}$ ) have mainly $\mathrm{Cd}-5 p$ and $\mathrm{O}_{\mathrm{i}}-2 p$ contributions, whereas the $\mathrm{O}_{\mathrm{i}}-2 p$ contribution gives rise to the unoccupied conduction band impurity level. It is interesting to notice that
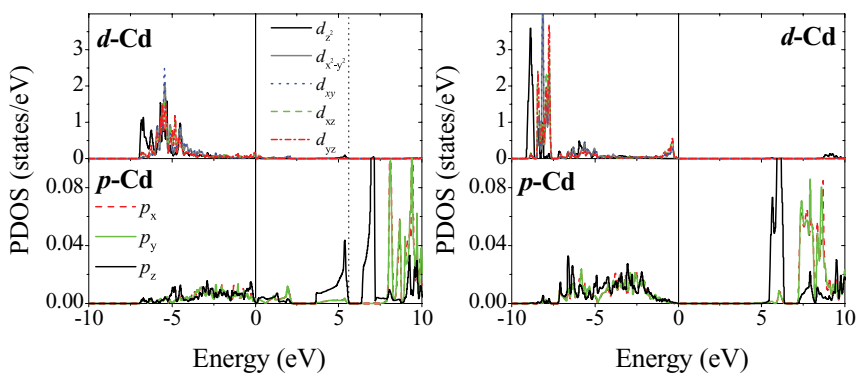

FIG. 8. (Color online) $d$ and $p$ partial density of states (PDOS) projected at the $\mathrm{Cd}$ site for $\left(\mathrm{Al}_{2} \mathrm{O}_{3}: \mathrm{Cd}_{\mathrm{i}}\right)^{0}$ (left) and $\left(\mathrm{Al}_{2} \mathrm{O}_{3}: \mathrm{Cd}_{\mathrm{i}}\right)^{2+}$ (right). The vertical lines are at the top of the valence band (solid) and at the highest occupied state (dotted). On the right, both lines are coincident.
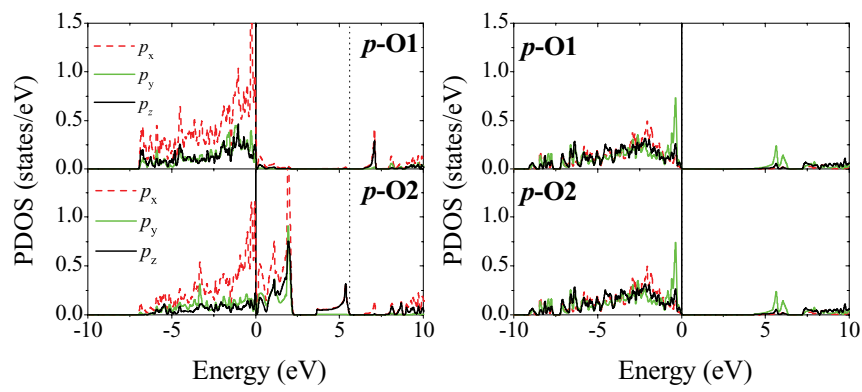

FIG. 9. (Color online) $p$ partial density of state (PDOS) projected at the $\mathrm{O} 1_{\mathrm{i}}$ and $\mathrm{O} 2 \mathrm{i}$ sites for the $\left(\mathrm{Al}_{2} \mathrm{O}_{3}: \mathrm{Cd}_{\mathrm{i}}\right)^{0}(\mathrm{left})$ and $\left(\mathrm{Al}_{2} \mathrm{O}_{3}: \mathrm{Cd}_{\mathrm{i}}\right)^{2+}$ (right). The vertical lines are at the top of the valence band (solid) and at the highest occupied state (dotted). On the right, both lines are coincident.

the $\mathrm{O} 2_{\mathrm{i}}$, which are farther than the $\mathrm{O}_{\mathrm{i}}$ (see Table III), give a larger contribution to the impurity related energy levels in the gap region. These states are very much modified when two electrons are removed from the system, as shown in Figs. 8 and 9 (right). In this case, the PDOSs at the $\mathrm{O}_{1}$ and $\mathrm{O} 2_{\mathrm{i}}$ are identical, accordingly with the final equilibrium distances shown in Table III. The effect of the removal of two electrons can be noticed in Fig. 7(c) as a "cleaning up" of the impurity related energy levels in the gap region.

\section{Impurity formation energies}

In order to further unravel the question of different structural scenarios, raised by the EFG results as shown in the previous sections, we performed energetic studies. The procedures used for these formation energy calculations are described in detail in the Appendix. In Fig. 10 we plot the formation energies, obtained using Eqs. (A20) and (A23), as a function of the Fermi energy level. For the $\mathrm{Al}_{2} \mathrm{O}_{3}: \mathrm{Cd}_{\mathrm{s}}$ system, the negatively charged state (ionized acceptor level) is the most stable. This charge state gives rise to an EFG coincident with the TDPAC experiments (see Table I). For the $\mathrm{Al}_{2} \mathrm{O}_{3}: \mathrm{Cd}_{\mathrm{i}}$ system, the charged state (ionized double donor level) is the most stable one for almost all values of $\varepsilon_{F}$. On the other hand, the EFG predicted for this charge state (see Table III) is clearly in disagreement with the TDPAC measurements. These results

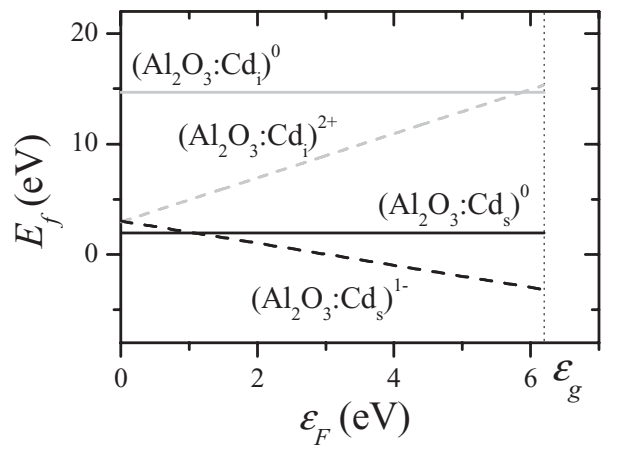

FIG. 10. Formation energies as a function of the Fermi energy level $\varepsilon_{F}\left(0 \leqslant \varepsilon_{F} \leqslant \varepsilon_{g}\right.$, where $\varepsilon_{g}$ is the band-gap energy). The black solid line correspond to $\left(\mathrm{Al}_{2} \mathrm{O}_{3}: \mathrm{Cd}_{\mathrm{s}}\right)^{0}$, the black dashed line to $\left(\mathrm{Al}_{2} \mathrm{O}_{3}: \mathrm{Cd}_{\mathrm{s}}\right)^{1-}$, the gray solid line to $\left(\mathrm{Al}_{2} \mathrm{O}_{3}: \mathrm{Cd}_{\mathrm{i}}\right)^{0}$ and the gray dashed line to $\left(\mathrm{Al}_{2} \mathrm{O}_{3}: \mathrm{Cd}_{\mathrm{i}}\right)^{2+}$. 
suggest that the interstitial Cd scenario would not be observed in this trace amount dilution limit, as in the samples used in the TDPAC experiment.

It should be noticed that, in a TDPAC experiment, the measured EFG is determined at a suitable probe atom, i.e., at the daughter isotope produced after the radioactive decay of the diffused, activated, or implanted radioactive isotope. In almost all cases, it is common knowledge that after this decay the daughter probe atom resides at the same crystallographic site as its parent. It is well known ${ }^{58}$ that ion implantation in oxides, sapphire among them, leaves the impurity-host system in a thermodynamic state far from the equilibrium. Therefore, structural disorder such as amorphization, point defects clusters and/or new species can arise, depending on multiple causes like implantation energy and doses, ion species, target temperature, etc.

After thermal-annealing the samples, to get rid of radiation damage and/or to redistribute the impurities, the ${ }^{111}$ In and ${ }^{111 m} \mathrm{Cd}$ probes in the TDPAC experiments would rest at the most stable sites. Some fingerprints of this thermal equilibrium situation are the near constancy of the EFG, its high monochromaticity, and reversibility as a function of temperature in a very wide temperature range. Hence, in the $\gamma-\gamma$ TDPAC experiments of Habenicht et al. ${ }^{30}$ and Penner et al. ${ }^{31}$ the ${ }^{111} \mathrm{Cd}$ probe would be localized at the site chosen by their parents, ${ }^{111 m} \mathrm{Cd}$ and ${ }^{111} \mathrm{In}$, when they entered into the single-crystalline host matrix. Hence, the energetic results discussed up to now have shown that, at least for ${ }^{111 m} \mathrm{Cd}$ TDPAC experiments, ${ }^{30}$ ${ }^{111} \mathrm{Cd}$ probes should be at substitutional Al sites. To thoroughly inspect the comparison with the ${ }^{111}$ In TDPAC experiments, ${ }^{30,31}$ we have then performed formation energy calculations for an In impurity at substitutional and interstitial sites in $\alpha-\mathrm{Al}_{2} \mathrm{O}_{3}$ for different charge states. The obtained results have shown that the substitutional Al site in the neutral charge state is the most energetically favorable situation for the inclusion of an ${ }^{111}$ In impurity in the $\alpha-\mathrm{Al}_{2} \mathrm{O}_{3}$.

All these results strongly suggest that in the three experiments the ${ }^{111} \mathrm{Cd}$ probes are at the substitutional $\mathrm{Al}$ site. This fact, along with the agreement between the experimentally determined EFG absolute value and that predicted by the ab initio calculations show that the ${ }^{111} \mathrm{Cd}$ impurity is at the substitutional site and is already ionized at $4 \mathrm{~K}$.

Finally, as mentioned before, the EFG sign, which would experimentally decide between both scenarios, cannot be determine in standard $\gamma-\gamma$ TDPAC experiments like the ones discussed here. ${ }^{30,31}$ The sign of a $V_{i j}$ component of the EFG tensor tells us if the electric-field component in the $i$ direction decreases or increases along the $j$ direction at the probe site. This sign can only be determined for the probes used in Refs. 30 and 31 in nonstandard $\gamma-\gamma$ TDPAC experiments in which the polarization of the second $\gamma$ ray is measured (unfortunately, these kinds of experiments are inefficient and hard to find in the literature). ${ }^{59}$

\section{CONCLUSIONS}

Using two state-of-the art (FP-LAPW + lo and PAW) $a b$ initio AE methods and by considering different charge states, we investigated the electronic structure, local environment, and EFG tensor at $\mathrm{Cd}$ impurities placed at interstitial and cationic substitutional sites in $\alpha-\mathrm{Al}_{2} \mathrm{O}_{3}$. After structural relaxations, with the electronic structure of the doped systems included in a self-consistent full-potential approach, both methods have provided the same electronic and equilibrium structure, and predictions for the EFG tensor. Cd introduces structural distortions in the host lattice, following a general trend already observed in other ${ }^{111} \mathrm{Cd}$-doped metal oxides, ${ }^{17,18,25-27}$ i.e., with the $\mathrm{Cd}$ atom trying to reconstruct the bond length that it has in its most stable oxide, $\mathrm{CdO}$.

We have shown that in both centers, substitutional and interstitial, $\mathrm{Cd}$ introduces impurity levels in the gap region. In the substitutional case, $\mathrm{Cd}$ introduces impurity levels near the top of the valence band, which are partially occupied in the neutral charge state. This center is a deep impurity and introduces an acceptor energy level with a (0/-) state transition energy, between $\left(\mathrm{Al}_{2} \mathrm{O}_{3}: \mathrm{Cd}_{\mathrm{s}}\right)^{0}$ and $\left(\mathrm{Al}_{2} \mathrm{O}_{3}: \mathrm{Cd}_{\mathrm{s}}\right)^{1-}$ at $\varepsilon_{v}^{\prime}+$ $0.9 \mathrm{eV}$, being $\varepsilon_{v}^{\prime}$ the top of the valence-band energy (as shown in Fig. 10). In the interstitial case, the impurity levels are spread out inside the band gap and are totally filled in the neutral charge state; we found that the impurity is only stable in the doubly positive charged state, suggesting that doping $\mathrm{Al}_{2} \mathrm{O}_{3}$ with $\mathrm{Cd}$ could, in principle, produce a very stable $n$-type material, a characteristic which is very desirable in the production of electronic devices.

Even in the event that during $\mathrm{Cd}$ implantation both kinds of centers could be produced, which could happen when the Fermi level of the material is experimentally tuned to be close to the top of the valence band, the double donor character of interstitial $\mathrm{Cd}$ guarantees a $n$-type $\mathrm{Al}_{2} \mathrm{O}_{3}$. This is due to the fact that our investigation shows that substitutional $\mathrm{Cd}$ is an acceptor and interstitial $\mathrm{Cd}$ is a double donor. The substitutional $\mathrm{Cd}$ negative charge state stability could also be produced by the continuous supply of electrons by the interstitial Cd. From the energetic studies, in the substitutional and interstitial $\mathrm{Cd}$ impurity localizations, we are led to infer that $\mathrm{Cd}$ could be a good candidate for several applications by tuning the charge state of the centers.

The predicted EFG absolute values at Cd impurities occupying the substitutional cation site (in the negatively charged state) and at the interstitial one (in the neutral charge state) are coincident. Comparing the literature TDPAC experiments and the presently obtained $a b$ initio EFG and formation energy calculations, we could resolve this indetermination. Our theoretical results have shown that ${ }^{111} \mathrm{Cd}$ impurities occupying the substitutional $\mathrm{Al}$ site in the $\alpha-\mathrm{Al}_{2} \mathrm{O}_{3}$ host, in the negative charge state, should be the correct scenario in this case, being the impurity already ionized at very low temperatures (around $4 \mathrm{~K}$ ). An experimental confirmation of the ${ }^{111} \mathrm{Cd}$ location in this trace dilute limit could be provided through the measurement of the EFG sign. Nevertheless, for the probes used in Refs. 30 and 31, the EFG sign can only be determined performing a nonstandard $\gamma-\gamma$ TDPAC experiment, in which the polarization of the second $\gamma$ ray has to be measured. Further RBS/C measurements, in the same conditions as the TDPAC experiments, i.e., with the same implantation energy, dose, thermal annealing, and composition of the $\alpha-\mathrm{Al}_{2} \mathrm{O}_{3}$ sample doped with ${ }^{111} \mathrm{In}$ or ${ }^{111 m} \mathrm{Cd}$, could also contribute to confirm the proposed scenario for ${ }^{111 m} \mathrm{Cd}$ and also for ${ }^{111} \mathrm{In}$ trace amount doping of $\mathrm{Al}_{2} \mathrm{O}_{3}$. Finally, our calculations, and comparison with the $\mathrm{RBS} / \mathrm{C}$ results 
in the highly doped samples, reveal that different amounts of In or $\mathrm{Cd}$ could lead to different impurity localization scenarios in the samples. This may contribute to tuning different electronic characters of the defect center-neutral or ionized acceptor in the substitutional case or ionized double donor in the interstitial one-which is desirable for potential applications.

\section{ACKNOWLEDGMENTS}

This work was partially supported by Consejo Nacional de Investigaciones Científicas y Técnicas (CONICET, PIP 0002), CNPq, CAPES, FAPESP, and was partially developed in the framework of the INEO Brazilian INCT project. This research made use of the HP-Parallel-Computing Bose Cluster, and the computational facilities of the Physics of Impurities in Condensed Matter (PhI) group at IFLP and Departamento de Física (UNLP), and LCCA-USP. We would like to thank Professor Wanda V. M. Machado for very fruitful discussions.

\section{APPENDIX: IMPURITY FORMATION ENERGY}

The formation energy of defects and/or impurities in crystals has been used to analyze the energetics of defects in several semiconductors ${ }^{60-62}$ and can be determined through the relative abundance of the atoms that constitute the system. Considering that impurities change the composition of the materials, the formation energy is expressed as a function of the chemical potentials of the atoms that constitute the material and that of the impurities. For Cd-doped $\alpha-\mathrm{Al}_{2} \mathrm{O}_{3}$, the defect energy formation is given by

$$
\begin{aligned}
E_{f}^{q}= & E^{q}\left(n_{\mathrm{Al}}, n_{\mathrm{O}}, n_{\mathrm{Cd}}\right)-n_{\mathrm{Al}} \mu_{\mathrm{Al}}-n_{\mathrm{O}} \mu_{\mathrm{O}} \\
& -n_{\mathrm{Cd}} \mu_{\mathrm{Cd}}+q\left(\varepsilon_{F}+\varepsilon_{v}^{\prime}\right) .
\end{aligned}
$$

Here, $E^{q}\left(n_{\mathrm{Al}}, n_{\mathrm{O}}, n_{\mathrm{Cd}}\right)$ is the total energy of the cell containing the defect in the charge state $q$, which contains $n_{\mathrm{Al}}$ atoms of $\mathrm{Al}, n_{\mathrm{O}}$ atoms of $\mathrm{O}$, and $n_{\mathrm{Cd}}$ atoms of $\mathrm{Cd} ; \mu_{\mathrm{Al}}, \mu_{\mathrm{O}}$, and $\mu_{\mathrm{Cd}}$ are their respective chemical potentials. $\varepsilon_{F}$ is the Fermi energy in the band gap relative to the top of the valence-band energy $\varepsilon_{v}^{\prime}$, with $0 \leqslant \varepsilon_{F} \leqslant \varepsilon_{g}$ ( $\varepsilon_{g}$ is the band-gap energy), and $\varepsilon_{v}^{\prime}=\varepsilon_{v}+\delta_{q}$, where $\varepsilon_{v}$ is the top of the valence-band energy of the pure system and $\delta_{q}$ lines up the band structures of the bulk material with and without the impurity. This correction $\delta_{q}$, in the top of the valence band, is necessary due to the charge-density inhomogeneity in the finite cell, which causes a Coulomb multipole interaction with its images; a uniform jellium background was implicitly considered to cancel out the long-range multipole interactions of charged supercells. ${ }^{61}$

The chemical potentials of the $\mathrm{Al}$ and $\mathrm{O}$ are not independent, and their variations are rigorously limited by the experimental conditions. Considering that both species are in thermal equilibrium at the $\alpha-\mathrm{Al}_{2} \mathrm{O}_{3}$ crystal, their chemical potentials at $T=0 \mathrm{~K}$ must obey

$$
\mu_{\mathrm{Al}_{2} \mathrm{O}_{3}}^{*}=2 \mu_{\mathrm{A} l}+3 \mu_{\mathrm{O}},
$$

where $\mu_{\mathrm{Al}_{2} \mathrm{O}_{3}}^{*}$ is the total energy per unit formula of $\alpha-\mathrm{Al}_{2} \mathrm{O}_{3}$, calculated theoretically with the optimized structure. The condition expressed in Eq. (A2) determines univocally the values of $\mu_{\mathrm{Al}}$ and $\mu_{\mathrm{O}}$. Once one of the potentials is fixed, the other will be automatically determined. Therefore, we can take $\mu_{\mathrm{Al}}$ as the independent variable, and the formation energy of the impurity will be a function of this chemical potential and the Fermi energy $\varepsilon_{F}$.

The chemical potentials show the loss of stoichiometry of a system and depend on different parameters, such as the partial pressures and growth conditions of the material. The chemical potentials $\mu_{\mathrm{Al}}$ and $\mu_{\mathrm{O}}$ in the $\alpha-\mathrm{Al}_{2} \mathrm{O}_{3}$ have a well-defined variation range and their values depend on the several phases formed by them. The maximum value of the $\mathrm{Al}$ is limited by its value in the metallic crystal $\left(\mu_{\mathrm{Al}}^{*}\right)$, which is its more stable phase, and is given by

$$
\mu_{\mathrm{Al}}^{*}=E_{T}(\mathrm{Al})
$$

where $E_{T}(\mathrm{Al})$ is the aluminum crystal total energy per atom, calculated in the face centered cubic unit cell. Therefore, the limit of the chemical potential is

$$
\mu_{\mathrm{Al}} \leqslant \mu_{\mathrm{Al}}^{*} \text {. }
$$

The maximum value of the $\mathrm{O}$ chemical potential is limited by its value in the reference phase, which we take as an $\mathrm{O}_{2}$ molecule,

$$
\mu_{\mathrm{O}} \leqslant \mu_{\mathrm{O}}^{*}=\frac{E_{T}\left(\mathrm{O}_{2}\right)}{2} .
$$

The $\alpha-\mathrm{Al}_{2} \mathrm{O}_{3}$ enthalpy formation $\left(\Delta_{f} H^{\mathrm{Al}_{2} \mathrm{O}_{3}}\right)$ is defined as the variation in the reaction where 1 mole of the substance is formed from the elements in their reference states, being negative for stable compounds, and is given by

$$
\Delta_{f} H^{\mathrm{Al}_{2} \mathrm{O}_{3}}=\mu_{\mathrm{Al}_{2} \mathrm{O}_{3}}^{*}-2 \mu_{\mathrm{Al}}^{*}-3 \mu_{\mathrm{O}}^{*} .
$$

Combining Eqs. (A2), and (A4)-(A6), the variation range for $\mathrm{Al}$ and $\mathrm{O}$ chemical potentials in $\alpha-\mathrm{Al}_{2} \mathrm{O}_{3}$ in terms of the $\alpha-\mathrm{Al}_{2} \mathrm{O}_{3}$ enthalpy of formation is

$$
\begin{gathered}
\mu_{\mathrm{Al}}^{*}+\frac{1}{2} \Delta_{f} H^{\mathrm{Al}_{2} \mathrm{O}_{3}} \leqslant \mu_{\mathrm{Al}} \leqslant \mu_{\mathrm{Al}}^{*}, \\
\mu_{\mathrm{O}}^{*}+\frac{1}{3} \Delta_{f} H^{\mathrm{Al}_{2} \mathrm{O}_{3}} \leqslant \mu_{\mathrm{O}} \leqslant \mu_{\mathrm{O}}^{*} .
\end{gathered}
$$

Introducing a $\gamma$ parameter, such that $0 \leqslant \gamma \leqslant 1$, these ranges can be rewritten as

$$
\mu_{\mathrm{Al}}=\mu_{\mathrm{Al}}^{*}+\frac{\gamma}{2} \Delta_{f} H^{\mathrm{Al}_{2} \mathrm{O}_{3}}
$$

and

$$
\mu_{\mathrm{O}}=\mu_{\mathrm{O}}^{*}+\frac{(1-\gamma)}{3} \Delta_{f} H^{\mathrm{Al}_{2} \mathrm{O}_{3}},
$$

such that when $\gamma=0\left(\mu_{\mathrm{Al}}=\mu_{\mathrm{Al}}^{*}\right)$ the neighborhood is $\mathrm{Al}$ rich, and when $\gamma=1\left(\mu_{\mathrm{O}}=\mu_{\mathrm{O}}^{*}\right)$ it is $\mathrm{O}$ rich.

In order to determine the variation range for the value of the $\mathrm{Cd}$ chemical potential, we need to take into account the different compounds that the impurity can form when interacting with the system. The upper limit of the $\mu_{\mathrm{Cd}}$ will be imposed by the chemical potential $\mu_{\mathrm{Cd}}^{*}$ of the hcp metallic crystal. Nevertheless, we also need to consider the possibility that some compounds are formed in equilibrium with the Cd-doped $\alpha-\mathrm{Al}_{2} \mathrm{O}_{3}$ crystal. Analogously to the $\alpha-\mathrm{Al}_{2} \mathrm{O}_{3}$ case [Eq. (A2)], assuming now a $\mathrm{CdO}$ formation, the enthalpy of 
formation is

$$
\Delta_{f} H^{\mathrm{CdO}}=\mu_{\mathrm{CdO}}^{*}-\mu_{\mathrm{Cd}}^{*}-\mu_{\mathrm{O}}^{*},
$$

where the $\mu_{\mathrm{Cd}}$ and $\mu_{\mathrm{O}}$ are not independent:

$$
\mu_{\mathrm{CdO}}^{*}=\mu_{\mathrm{Cd}}+\mu_{\mathrm{O}} .
$$

From Eqs. (A11) and (A12) we can obtain the expression for the $\mu_{\mathrm{Cd}}$ variation when $\mathrm{CdO}$ is the compound produced in equilibrium with $\mathrm{Cd}$-doped $\alpha-\mathrm{Al}_{2} \mathrm{O}_{3}$ :

$$
\mu_{\mathrm{Cd}}=\mu_{\mathrm{Cd}}^{*}+\left(\mu_{\mathrm{O}}^{*}-\mu_{\mathrm{O}}\right)+\Delta_{f} H^{\mathrm{CdO}} .
$$

Substituting in this equation the expression for $\left(\mu_{\mathrm{O}}^{*}-\mu_{\mathrm{O}}\right)$ from Eq. (A10),

$$
\mu_{\mathrm{Cd}}=\mu_{\mathrm{Cd}}^{*}-\frac{(1-\gamma)}{3} \Delta_{f} H^{\mathrm{Al}_{2} \mathrm{O}_{3}}+\Delta_{f} H^{\mathrm{CdO}},
$$

showing that the $\mu_{\mathrm{Cd}}$ variation range depends on the enthalpies of formation of the two compounds in equilibrium: $\alpha-\mathrm{Al}_{2} \mathrm{O}_{3}$ and $\mathrm{CdO}$. Since $\mu_{\mathrm{Cd}}-\mu_{\mathrm{Cd}}^{*} \leqslant 0$, Eq. (A14) is valid for $\gamma=1$. For $\gamma=0$, it will only be valid if

$$
\Delta_{f} H^{\mathrm{CdO}} \leqslant \frac{1}{3} \Delta_{f} H^{\mathrm{Al}_{2} \mathrm{O}_{3}} .
$$

Otherwise there will be a value for $\gamma\left(\gamma_{\min }\right)$ that must satisfy

$$
\Delta_{f} H^{\mathrm{CdO}}-\frac{\left(1-\gamma_{\min }\right)}{3} \Delta_{f} H^{\mathrm{Al}_{2} \mathrm{O}_{3}}=0,
$$

and therefore the variation range for $\gamma$ is

$$
0 \leqslant 1-\frac{\Delta_{f} H^{\mathrm{CdO}}}{\frac{1}{3} \Delta_{f} H^{\mathrm{Al}_{2} \mathrm{O}_{3}}}=\gamma_{\min } \leqslant \gamma \leqslant 1 .
$$

The calculated values of the $\alpha-\mathrm{Al}_{2} \mathrm{O}_{3}$ and $\mathrm{CdO}$ enthalpies of formation are $\Delta_{f} H^{\mathrm{Al}_{2} \mathrm{O}_{3}}=-1.089 \mathrm{Ry}$ and $\Delta_{f} H^{\mathrm{CdO}}=$ $-0.1660 \mathrm{Ry}$, respectively. Therefore $0.543 \leqslant \gamma \leqslant 1$. The calculated $\gamma_{\min }=0.543$ is in excellent agreement with $\gamma_{\text {min expt }}=$ $0.537(1)$, which is the value obtained from Eq. (A17) using the experimental $\Delta_{f} H_{\mathrm{expt}}^{\mathrm{Al}_{2} \mathrm{O}_{3}}=-1.276(1) \mathrm{Ry}$ and $\Delta_{f} H_{\mathrm{expt}}^{\mathrm{CdO}}=$ $-0.1968(4)$ Ry values. ${ }^{63}$

\section{Formation energy for $\mathrm{Cd}$ in the Al substitutional site}

In accordance with Eq. (A1) the formation energy of a $\mathrm{Cd}$ impurity in an Al substitutional site, with charge state $q$, is given by

$$
\begin{aligned}
E_{f}\left(\mathrm{Al}_{2} \mathrm{O}_{3}: \mathrm{Cd}_{\mathrm{s}}\right)^{q}= & E\left(\mathrm{Al}_{2} \mathrm{O}_{3}: \mathrm{Cd}_{\mathrm{s}}\right)^{q}-E\left(\mathrm{Al}_{2} \mathrm{O}_{3}\right) \\
& +\mu_{\mathrm{Al}}-\mu_{\mathrm{Cd}}+q\left(\varepsilon_{F}+\varepsilon_{v}^{\prime}\right),
\end{aligned}
$$

where $E\left(\mathrm{Al}_{2} \mathrm{O}_{3}: \mathrm{Cd}_{\mathrm{s}}\right)^{q}$ and $E\left(\mathrm{Al}_{2} \mathrm{O}_{3}\right)$ are the total energies of the substitutional $\mathrm{Cd}$-doped $\alpha-\mathrm{Al}_{2} \mathrm{O}_{3}$ cell in a $q$ charge state and of the perfect cell, respectively, both with the same number of atoms. Using $\mu_{\mathrm{Al}}$ and $\mu_{\mathrm{Cd}}$ from Eqs. (A9) and (A14) we have

$$
\begin{aligned}
E_{f}\left(\mathrm{Al}_{2} \mathrm{O}_{3}: \mathrm{Cd}_{\mathrm{s}}\right)^{q} & \\
= & E\left(\mathrm{Al}_{2} \mathrm{O}_{3}: \mathrm{Cd}_{\mathrm{s}}\right)^{q}-E\left(\mathrm{Al}_{2} \mathrm{O}_{3}\right)+\mu_{\mathrm{Al}}^{*}+\frac{\gamma}{2} \Delta_{f} H^{\mathrm{Al}_{2} \mathrm{O}_{3}} \\
& -\mu_{\mathrm{Cd}}^{*}+\frac{(1-\gamma)}{3} \Delta_{f} H^{\mathrm{Al}_{2} \mathrm{O}_{3}}-\Delta_{f} H^{\mathrm{CdO}}+q\left(\varepsilon_{F}+\varepsilon_{v}^{\prime}\right)
\end{aligned}
$$

with $0.543 \leqslant \gamma \leqslant 1$.

As Cd is substituting an $\mathrm{Al}$ atom, it is reasonable to imagine that this situation occurs in an oxygen-rich neighborhood (poor in $\mathrm{Al}$ ). Using $\gamma=1$,

$$
\begin{aligned}
E_{f}\left(\mathrm{Al}_{2} \mathrm{O}_{3}: \mathrm{Cd}_{\mathrm{s}}\right)^{q}= & E\left(\mathrm{Al}_{2} \mathrm{O}_{3}: \mathrm{Cd}_{\mathrm{s}}\right)^{q}-E\left(\mathrm{Al}_{2} \mathrm{O}_{3}\right) \\
& +\mu_{\mathrm{Al}}^{*}+\frac{1}{2} \Delta_{f} H^{\mathrm{Al}_{2} \mathrm{O}_{3}}-\mu_{\mathrm{Cd}}^{*} \\
& -\Delta_{f} H^{\mathrm{CdO}}+q\left(\varepsilon_{F}+\varepsilon_{v}^{\prime}\right) .
\end{aligned}
$$

We notice that if we would had taken the metallic $\mathrm{Cd}$ as the reference element instead of $\mathrm{CdO}$, the expression for the formation energy (also with $\gamma=1$ ) would have been

$$
\begin{aligned}
E_{f}\left(\mathrm{Al}_{2} \mathrm{O}_{3}: \mathrm{Cd}_{\mathrm{s}}\right)^{q}= & E\left(\mathrm{Al}_{2} \mathrm{O}_{3}: \mathrm{Cd}_{\mathrm{s}}\right)^{q}-E\left(\mathrm{Al}_{2} \mathrm{O}_{3}\right)+\mu_{\mathrm{Al}}^{*} \\
& +\frac{1}{2} \Delta_{f} H^{\mathrm{Al}_{2} \mathrm{O}_{3}}-\mu_{\mathrm{Cd}}^{*}+q\left(\varepsilon_{F}+\varepsilon_{v}^{\prime}\right) .
\end{aligned}
$$

\section{Formation energy for $\mathrm{Cd}$ in the interstitial site}

The formation energy of a $\mathrm{Cd}$ impurity in an interstitial site in $\alpha-\mathrm{Al}_{2} \mathrm{O}_{3}$, with a charge state $q$, is given by

$$
\begin{aligned}
E_{f}\left(\mathrm{Al}_{2} \mathrm{O}_{3}: \mathrm{Cd}_{\mathrm{i}}\right)^{q}= & E\left(\mathrm{Al}_{2} \mathrm{O}_{3}: \mathrm{Cd}_{\mathrm{i}}\right)^{q}-E\left(\mathrm{Al}_{2} \mathrm{O}_{3}\right) \\
& -\mu_{\mathrm{Cd}}+q\left(\varepsilon_{F}+\varepsilon_{v}^{\prime}\right),
\end{aligned}
$$

where $E\left(\mathrm{Al}_{2} \mathrm{O}_{3}: \mathrm{Cd}_{\mathrm{i}}\right)^{q}$ is the total energy of the interstitial Cd-doped $\alpha-\mathrm{Al}_{2} \mathrm{O}_{3}$ cell in a $q$ charge state. Using $\mu_{\mathrm{Cd}}$ from Eq. (A14) and the $\mathrm{CdO}$ as the reference compound we have

$$
\begin{aligned}
E_{f}\left(\mathrm{Al}_{2} \mathrm{O}_{3}: \mathrm{Cd}_{\mathrm{i}}\right)^{q}= & E\left(\mathrm{Al}_{2} \mathrm{O}_{3}: \mathrm{Cd}_{\mathrm{i}}\right)^{q}-E\left(\mathrm{Al}_{2} \mathrm{O}_{3}\right)-\mu_{\mathrm{Cd}}^{*} \\
& -\Delta_{f} H^{\mathrm{CdO}}+q\left(\varepsilon_{F}+\varepsilon_{v}^{\prime}\right) .
\end{aligned}
$$

Again, if we had taken the metallic $\mathrm{Cd}$ as the reference element instead of $\mathrm{CdO}$, the expression for the formation energy (also with $\gamma=1$ ) would have been

$$
\begin{aligned}
E_{f}\left(\mathrm{Al}_{2} \mathrm{O}_{3}: \mathrm{Cd}_{\mathrm{i}}\right)^{q}= & E\left(\mathrm{Al}_{2} \mathrm{O}_{3}: \mathrm{Cd}_{\mathrm{i}}\right)^{q}-E\left(\mathrm{Al}_{2} \mathrm{O}_{3}\right) \\
& -\mu_{\mathrm{Cd}}^{*}+q\left(\varepsilon_{F}+\varepsilon_{v}^{\prime}\right) .
\end{aligned}
$$

${ }^{1}$ G. Kresse, M. Schmid, E. Napetschnig, M. Shishkin, L. Kohler, and P. Varga, Science 308, 1440 (2005).

${ }^{2}$ H. Li, J. Feng, W. Zhang, W. Jiang, H. Gu, and J. R. Smith, Phys. Rev. B 80, 205422 (2009).

${ }^{3}$ T. S. Santos, J. S. Lee, P. Migdal, I. C. Lekshmi, B. Satpati, and J. S. Moodera, Phys. Rev. Lett. 98, 016601 (2007).
${ }^{4}$ V. Dediu, L. E. Hueso, I. Bergenti, A. Riminucci, F. Borgatti, P. Graziosi, C. Newby, F. Casoli, M. P. D. Jong, C. Taliani, and Y. Zhan, Phys. Rev. B 78, 115203 (2008).

${ }^{5}$ M. Grobosch, C. Schmidt, W. J. M. Naber, W. G. van der Wiel, and M. Knupfer, Synth. Met. 160, 238 (2010). 
${ }^{6}$ A. Lehnert, S. Rusponi, M. Etzkorn, S. Ouazi, P. Thakur, and H. Brune, Phys. Rev. B 81, 104430 (2010); M. Schmid, G. Kresse, A. Buchsbaum, E. Napetschnig, S. Gritschneder, M. Reichling, and P. Varga, Phys. Rev. Lett. 99, 196104 (2007).

${ }^{7}$ C. Verdozzi, D. R. Jennison, P. A. Schultz, M. P. Sears, J. C. Barbour, and B. G. Potter, Phys. Rev. Lett. 80, 5615 (1998).

${ }^{8}$ K. Nassau, Color for Science, Art and Technology (Elsevier Science, Amsterdam, 1998).

${ }^{9}$ S. Intarasiri, D. Bootkul, L. D. Yu, T. Kamwanna, S. Singkarat, and T. Vilaithong, Surf. Coat. Technol. 203, 2788 (2009).

${ }^{10}$ D. Bootkul, S. Intarasiri, T. Kamwanna, U. Tippawan, and S. Singkarat, in Proceedings of the 6th Annual Conference of the Thai Physics Society, SPC2011 (Pattaya, Chonburi, Thailand, 2011), p. 264.

${ }^{11}$ J. F. Boily and J. B. Fein, Geochim. Cosmochim. Acta 60, 2929 (1996); T. K. Sen and M. V. Sarzali, Chem. Eng. J. 142, 256 (2008).

${ }^{12}$ M. Springis, P. Kulis, A. Veispals, and I. Tale, Radiat. Meas. 24, 453 (1995).

${ }^{13}$ G. Schatz and A. Weidinger, Nuclear Condensed Matter Physics: Nuclear Methods and Applications (Wiley, Chichester, UK, 1996).

${ }^{14}$ E. N. Kaufmann and R. J. Vianden, Rev. Mod. Phys. 51, 161 (1979).

${ }^{15}$ A. Lerf and T. Butz, Angew. Chem., Int. Ed. Engl. 26, 110 (1987); T. Klas, J. Voigt, W. Keppner, R. Wesche, and G. Schatz, Phys. Rev. Lett. 57, 1068 (1986); R. Vianden and U. Feuser, ibid. 61, 1981 (1988); N. Achtziger and W. Witthuhn, Phys. Rev. B 47, 6990 (1993); D. Lupascu, M. Uhrmacher, and K. P. Lieb, J. Phys.: Condens. Matter 6, 10445 (1994); J. Meersschaut, C. L'abbe, M. Rots, and S. D. Bader, Phys. Rev. Lett. 87, 107201 (2001); J. M. Ramallo-López, M. Rentería, E. E. Miró, F. G. Requejo, and A. Traverse, ibid. 91, 108304 (2003); M. Forker, S. Muller, P. de la Presa, and A. F. Pasquevich, Phys. Rev. B 68, 014409 (2003).

${ }^{16}$ S. Lany, P. Blaha, J. Hamann, V. Ostheimer, H. Wolf, and T. Wichert, Phys. Rev. B 62, R2259 (2000).

${ }^{17}$ L. A. Errico, G. Fabricius, M. Rentería, P. de la Presa, and M. Forker, Phys. Rev. Lett. 89, 055503 (2002).

${ }^{18}$ L. A. Errico, G. Fabricius, and M. Rentería, Phys. Rev. B 67, 144104 (2003), and references therein.

${ }^{19}$ L. A. Terrazos, H. M. Petrilli, M. Marszalek, H. Saitovich, P. R. J. Silva, P. Blaha, and K. Schwarz, Solid State Commun. 121, 525 (2002).

${ }^{20}$ M. Forker, P. de la Presa, W. Hoffbauer, S. Schalabach, M. Bruns, and D. B. Szabó, Phys. Rev. B 77, 054108 (2008).

${ }^{21}$ Defect and Diffusion Studied Using PAC Spectroscopy, edited by H. Jaeger and M. O. Zacate (Trans Tech Publications Ltd., Zurich, Switzerland, 2011).

${ }^{22}$ H. Akai, M. Akai, S. Blügel, B. Drittler, H. Ebert, K. Terakura, R. Zeller, and P. H. Dederichs, Prog. Theor. Phys. Suppl. 101, 11 (1990).

${ }^{23}$ G. N. Darriba, L. A. Errico, P. D. Eversheim, G. Fabricius, and M. Rentería, Phys. Rev. B 79, 115213 (2009).

${ }^{24}$ P. Hohenberg and W. Kohn, Phys. Rev. 136, B864 (1964); W. Kohn and L. J. Sham, ibid. 140, A1133 (1965).

${ }^{25}$ L. A. Errico, G. Fabricius, and M. Rentería, Hyperfine Interact. 136/137, 749 (2001).

${ }^{26}$ L. A. Errico, M. Rentería, G. Fabricius, and G. N. Darriba, Hyperfine Interact. 158, 63 (2004).

${ }^{27}$ L. A. Errico, M. Rentería, A. G. Bibiloni, and G. N. Darriba, Phys. Status Solidi C 2, 3576 (2005).
${ }^{28}$ M. Rentería, G. N. Darriba, L. A. Errico, E. L. Muñoz, and P. D. Eversheim, Phys. Status Solidi B 242, 1928 (2005).

${ }^{29}$ H. Höhler, N. Atodiresei, K. Schroeder, R. Zeller, and P. H. Dederichs, Phys. Rev. B 71, 035212 (2005).

${ }^{30}$ S. Habenicht, D. Lupascu, M. Neubauer, M. Uhrmacher, and K. P. Lieb, Hyperfine Interact. 120/121, 445 (1999).

${ }^{31}$ J. Penner and R. Vianden, Hyperfine Interact. 158, 389 (2005).

${ }^{32}$ G. C. Farlow, P. S. Sklad, C. W. White, and C. J. McHargue, J. Mater. Res. 5, 1502 (1990).

${ }^{33}$ J. G. Marques, A. A. Melo, J. C. Soares, E. Alves, M. F. da Silva, and K. Freitag, Nucl. Instrum. Methods Phys. Res., Sect. B 106 , 602 (1995).

${ }^{34}$ D. Wiarda, M. Uhrmacher, A. Bartos, and K. P. Lieb, J. Phys.: Condens. Matter 5, 4111 (1992).

${ }^{35}$ A. F. Pasquevich, A. G. Bibiloni, C. P. Massolo, M. Rentería, J. A. Vercesi, and K. Freitag, Phys. Rev. B 49, 14331 (1994).

${ }^{36}$ R. M. Sternheimer and H. M. Foley, Phys. Rev. 92, 1460 (1953); 102, 731 (1956); R. M. Sternheimer, ibid. 95, 736 (1954); 96, 951 (1954); 130, 1423 (1963); 132, 1637 (1963); 146, 140 (1966); 159, 266 (1967).

${ }^{37}$ E. Sjöstedt, L. Nordström, and D. J. Singh, Solid State Commun. 114, 15 (2000); G. K. H. Madsen, P. Blaha, K. Schwarz, E. Sjöstedt, and L. Nordström, Phys. Rev. B 64, 195134 (2001).

${ }^{38}$ P. E. Blöchl, Phys. Rev. B 50, 17953 (1994); P. E. Blöchl, C. J. Först, and J. Schimpl, Bull. Mater. Sci. 26, 33 (2003).

${ }^{39}$ L. A. Errico, M. Rentería, and H. M. Petrilli, Phys. Rev. B 75, 155209 (2007)

${ }^{40}$ P. Blaha, K. Schwarz, and P. H. Dederichs, Phys. Rev. B 37, 2792 (1988).

${ }^{41}$ K. Schwarz, C. Ambrosch-Draxl, and P. Blaha, Phys. Rev. B 42, 2051 (1990).

${ }^{42}$ H. M. Petrilli and S. Frota-Pessôa, J. Phys. F 15, 2307 (1985).

${ }^{43}$ S. Cottenier, V. Bellini, M. Çakmak, F. Manghi, and M. Rots, Phys. Rev. B 70, 155418 (2004).

${ }^{44}$ F. Izumi, H. Asano, H. Murata, and N. Watanabe, J. Appl. Crystallogr. 20, 411 (1987).

${ }^{45}$ P. Blaha, K. Schwarz, G. Madsen, D. Kvasnicka, and J. Luitz, WIEN2k, An Augmented Plane Wave Plus Local Orbitals Program for Calculating Crystal Properties (Karlheinz Schwarz, Technical Universität Wien, Austria, 1999).

${ }^{46}$ R. Car and M. Parrinello, Phys. Rev. Lett. 55, 2471 (1985).

${ }^{47}$ J. P. Perdew, K. Burke, and M. Ernzerhof, Phys. Rev. Lett. 77, 3865 (1996).

${ }^{48}$ P. E. Blöchl, J. Chem. Phys. 103, 7422 (1995).

${ }^{49}$ H. M. Petrilli, P. E. Blöchl, P. Blaha, and K. Schwarz, Phys. Rev. B 57, 14690 (1998).

${ }^{50}$ B. Kohler, S. Wilker, M. Sheffler, R. Couba, and C. AmbroschDraxl, Comput. Phys. Commun. 94, 31 (1996).

${ }^{51}$ R. V. Pound, Phys. Rev. 79, 685 (1950).

${ }^{52}$ K. Matsunaga, T. Tanaka, T. Yamamoto, and Y. Ikuhara, Phys. Rev. B 68, 085110 (2003).

${ }^{53}$ Y.-N. Xu, Z.-Q. Gu, X.-F. Zhong, and W. Y. Ching, Phys. Rev. B 56, 7277 (1997).

${ }^{54}$ I. Tanaka, K. Tatsumi, M. Nakano, H. Adachi, and F. Oba, J. Am. Ceram. Soc. 85, 68 (2002).

${ }^{55}$ W. Y. Ching and Y. N. Xu, J. Am. Ceram. Soc. 77, 404 (1994). 
${ }^{56}$ R. H. French, J. Am. Ceram. Soc. 73, 477 (1990).

${ }^{57}$ R. D. Shannon, Acta Crystallogr. Sect. A 32, 751 (1976).

${ }^{58}$ C. J. McHargue and L. J. Romana, Nucl. Instrum. Methods Phys. Res., Sect. B 166/167, 193 (2000); H. Naramoto, C. J. McHargue, C. W. White, J. M. Williams, O. W. Holland, M. M. Abraham, and B. R. Appleton, Nucl. Instrum. Methods Phys. Res. 209/210, 1159 (1983); H. Naramoto, C. W. White, J. M. Williams, C. J. McHargue, O. W. Holland, M. M. Abraham, and B. R. Appleton, J. Appl. Phys. 54, 683 (1983).
${ }^{59}$ R. S. Raghavan, P. Raghavan, and E. N. Kaufmann, Phys. Rev. C 12, 2022 (1975).

${ }^{60}$ R. Larico, J. F. Justo, W. V. M. Machado, and L. V. C. Assali, Physica B 340, 84 (2003).

${ }^{61}$ L. V. C. Assali, W. V. M. Machado, and J. F. Justo, Phys. Rev. B 69, 155212 (2004).

${ }^{62}$ F. Ayres, L. V. C. Assali, W. V. M. Machado, and J. F. Justo, Appl. Phys. Lett. 88, 011918 (2006).

${ }^{63}$ D. R. Lide, Handbook of Chemistry and Physics, 78th ed. (CRC Press, Boca Raton, FL, 1997-1998). 